\title{
The contribution of soil biogenic NO and HONO emissions from a managed hyperarid ecosystem to the regional $\mathrm{NO}_{x}$ emissions during growing season
}

\author{
Buhalqem Mamtimin $^{1,2}$, Franz X. Meixner ${ }^{2}$, Thomas Behrendt ${ }^{2,4}$, Moawad Badawy ${ }^{2,3}$, and Thomas Wagner ${ }^{1}$ \\ ${ }^{1}$ Max Planck Institute for Chemistry, Satellite Research Group, Mainz, Germany \\ ${ }^{2}$ Max Planck Institute for Chemistry, Biogeochemistry Department, Mainz, Germany \\ ${ }^{3}$ Department of Geography, Faculty of Arts, Ain Shams University, Cairo, Egypt \\ ${ }^{4}$ Max Planck Institute for Biogeochemistry, Jena, Germany \\ Correspondence to: Buhalqem Mamtimin (buhalqem.mamtimin@mpic.de)
}

Received: 16 November 2015 - Published in Atmos. Chem. Phys. Discuss.: 10 December 2015

Revised: 5 July 2016 - Accepted: 15 July 2016 - Published: 11 August 2016

\begin{abstract}
A study was carried out to understand the contributions of soil biogenic NO emissions from managed (fertilized and irrigated) hyperarid ecosystems in NW China to the regional $\mathrm{NO}_{x}$ emissions during the growing season. Soil biogenic net potential NO fluxes were quantified by laboratory incubation of soil samples from the three dominating ecosystems (desert, cotton, and grape fields). Regional biogenic NO emissions were calculated bottom-up hourly for the entire growing season (April-September 2010) by considering corresponding land use, hourly data of soil temperature, gravimetric soil moisture, and fertilizer enhancement factors. The regional $\mathrm{HONO}$ emissions were estimated using the ratio of the optimum condition $\left(\left(F_{\mathrm{N}_{\text {,opt }}}(\mathrm{HONO})\right.\right.$ to $F_{\mathrm{N}}$,opt (NO)).

Regional anthropogenic $\mathrm{NO}_{x}$ emissions were calculated bottom-up from annual statistical data provided by regional and local government bureaus which have been downscaled to monthly value. Regional top-down emission estimates of $\mathrm{NO}_{x}$ were derived on the monthly basis from satellite observations (OMI) of tropospheric vertical $\mathrm{NO}_{2}$ column densities and prescribed values of the tropospheric $\mathrm{NO}_{x}$ lifetime. In order to compare the top-down and bottom-up emission estimates, all emission estimates were expressed in terms of mass of atomic nitrogen. Consequently, monthly top-down $\mathrm{NO}_{x}$ emissions (total) were compared with monthly bottomup $\mathrm{NO}_{x}$ emissions (biogenic + anthropogenic) for the time of the satellite overpass (around 13:00 LT) with the consideration of the diurnal cycle of bottom-up estimates. Annual
\end{abstract}

variation in total Tohsun Oasis $\mathrm{NO}_{x}$ emissions is characterized by a strong peak in winter (December-February) and a secondary peak in summer (June-August). During summer, soil biogenic emissions were from equal to double that of related anthropogenic emissions, and grape soils were the main contributor to soil biogenic emissions, followed by cotton soils, while emissions from the desert were negligible. The top-down and bottom-up emission estimates were shown to be useful methods to estimate the monthly/seasonal cycle of the total regional $\mathrm{NO}_{x}$ emissions. The resulting total $\mathrm{NO}_{x}$ emissions show a strong peak in winter and a secondary peak in summer, and the second maximum in summer was only found if the soil emissions were taken into account, which provides confidence in both completely independent methods. Despite the regional character of these findings, particularly the second maximum in summer provides substantial evidence to hypothesize that biogenic emissions from soils of managed drylands (irrigated and fertilized) in the growing period may be much more important contributors to regional $\mathrm{NO}_{x}$ budgets of dryland regions than thought before.

\section{Introduction}

Atmospheric carbon monoxide, methane, and volatile organic compounds are oxidized by the hydroxyl and other radicals through various catalytic cycles (Crutzen, 1987). In these cycles, nitrogen oxides $\left(\mathrm{NO}_{x}=\mathrm{NO}+\mathrm{NO}_{2}\right)$ are 
key catalysts, and their ambient concentrations determine whether ozone $\left(\mathrm{O}_{3}\right)$ is generated or destroyed in the troposphere (Chameides et al., 1992). Ozone is usually generated in polluted, industrialized regions, where ambient levels of $\mathrm{NO}_{x}$ are high. Moreover, the intensification of agriculture is associated with increased NO emissions, which also causes an increase in available nitrogen in the atmosphere (Denman et al., 2007). $\mathrm{NO}_{x}$ in the troposphere originates mostly as $\mathrm{NO}$, which reaches a photo-stationary equilibrium with $\mathrm{NO}_{2}$ within a few minutes. The current evolution of anthropogenic as well as biogenic $\mathrm{NO}_{x}$ sources triggers a potential increase in global tropospheric $\mathrm{O}_{3}$ concentrations. According to recent estimates (Kasibhatla et al., 1993; Davidson and Kingerlee, 1997; Denman et al., 2007; Feig et al., 2008), anthropogenic sources amount to $45-67 \%$ of the mid-2000s total global $\mathrm{NO}_{x}$ emissions ( $42-47 \mathrm{Tg} \mathrm{a}^{-1}$, in terms of mass of $\mathrm{N}$ ), and other globally important sources are soil biogenic NO emissions (10-40\%), biomass burning (13-29\%), and lightning $(5-16 \%)$. The considerable uncertainty about the range of soil biogenic NO emissions stems from widely differing estimates of the NO emissions. Based on field measurements worldwide Davidson and Kingerlee (1997) estimated the global NO soil source strength to be $21 \mathrm{Tg} \mathrm{a}^{-1}$ (with an error margin of 4 to $10 \mathrm{Tg} \mathrm{a}^{-1}, 40 \%$ of the total), while the fourth IPCC estimate is $8.9 \mathrm{Tg} \mathrm{a}^{-1}$ (Denman et al., 2007), which is higher than the third IPCC estimate of $5.6 \mathrm{Tg} \mathrm{a}^{-1}$ (IPCC, 2001). Moreover, the uncertainties in the NO emission data from semiarid, arid, and hyperarid regions are very large (mainly due to a very small number of measurements being available). In this context, one should be aware that approximately $40 \%$ of planet Earth's total land surface consists of semiarid, arid, and hyperarid land and more than $30 \%$ of the world's inhabitants live in arid, semiarid, and hyperarid regions (Lai, 2001).

In many parts of the world's drylands, the land cover is strongly changing due to the encroachment of deserts by bushy vegetation (desert $\rightarrow$ dryland farming; bushy vegetation $\rightarrow$ dryland farming). This leads to and will result in dramatic changes in soil microbial production and consumption of NO. Consequently, it will have a strong impact on the regional budgets of those reactive trace gasses $\left(\mathrm{NO}_{x}, \mathrm{O}_{3}\right.$, volatile organic compounds (VOCs), etc.) which are involved in the tropospheric oxidizing capacity. For this reason, it is necessary to quantify the NO emissions from both natural and agricultural managed soils of the drylands.

Recently, Oswald et al. (2013) pointed out that (a) the release of odd reactive nitrogen gasses from soils due to microbial activity is not confined to NO only, (b) about equal amounts of gaseous nitrous acid (HONO) are simultaneously emitted along with NO, and (c) HONO emissions from soils are one of the most relevant sources in arid areas with regard to tropospheric chemistry. In addition, daytime NO production from HONO photolysis contributes to the total production of $\mathrm{NO}_{x}$ emissions. Therefore, it is meaningful to con- sider HONO emissions for any estimates of biogenic total reactive nitrogen emissions from soil.

The biogenic emissions of NO (as well as HONO) depend crucially on soil temperature and soil moisture because these factors affect the availability of organic compounds and the microbial activity in the soil (Conrad, 1996; Meixner and Yang, 2006; Ludwig et al., 2001; Oswald et al., 2013). Sufficient soil moisture, high soil temperatures, and regular supply of nutrients (N-containing fertilizer) are optimum conditions for soil biogenic NO (and HONO) emissions, particularly from arid and hyperarid land.

An oasis is an area used for agriculture in a desert region. The intensification (economically driven) of oasis agriculture, however, needs enlargement of the arable land area, enhancement of necessary irrigation, and increased fertilizer use, which leads inevitably to increasing soil biogenic NO (and HONO) emissions. Microbial processes which underlie NO production (and NO consumption) in soils (e.g., nitrification, denitrification) are confined to the uppermost soil layers ( $<0.05 \mathrm{~m}$ depth, Rudolph et al., 1996). The most direct method for the characterization of these processes and the quantification of the NO (and HONO) release from soils is usually realized by laboratory incubation of soil samples taken from topsoil layers. In those laboratory incubation systems, the net release rate of NO is determined from the NO concentration difference between incoming and outgoing air. The application of this method in the past has proved that the release of NO can be described by specific and unique functions of soil moisture, soil temperature, and ambient NO concentration (Otter et al., 1999; van Dijk et al., 2002; Meixner and Yang, 2006; Feig et al., 2008; Behrendt et al., 2014; Mamtimin et al., 2015).

Due to the industrialization of Chinese drylands and also the intensification of their agriculture, not only are significant anthropogenic $\mathrm{NO}_{x}$ emissions from growing oasis cities expected but also current and future land use will intensify the "hot spot" character of soil biogenic NO emissions from oases. The general aim of the present study is to determine the contributions of soil biogenic NO emissions of a selected oasis in the Taklimakan Desert to the regional $\mathrm{NO}_{x}$ emissions during the growing season. For that, we concentrate (a) on the determination of net potential biogenic NO fluxes derived from laboratory incubation measurements of soil samples; (b) on the bottom-up calculation of regional biogenic NO and HONO emissions for the growing season, taking into account the corresponding land use, soil temperatures, gravimetric soil moistures, and fertilizer factors; (c) on the bottom-up estimation of regional anthropogenic $\mathrm{NO}_{x}$ emissions of the oasis based on energy consumption and $\mathrm{NO}_{x}$ emission factors of different energy sectors and fuel types; (d) on the top-down calculation of regional total $\mathrm{NO}_{x}$ emissions from satellite observations (OMI) of the vertical $\mathrm{NO}_{2}$ column densities and prescribed values of tropospheric $\mathrm{NO}_{x}$ lifetime; and (e) on the quantitative comparison of regional total $\mathrm{NO}_{x}$ 


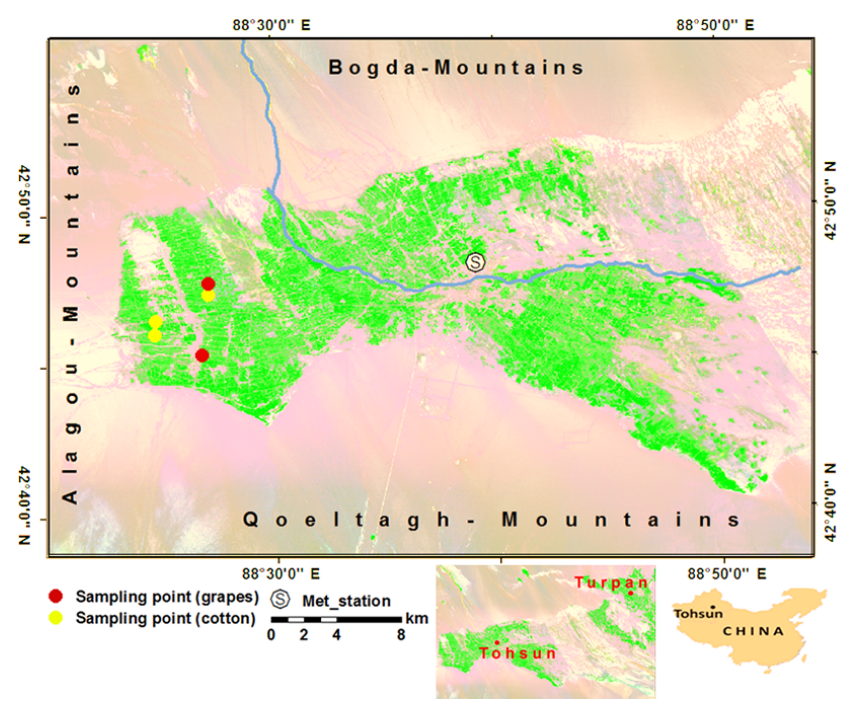

Figure 1. Satellite map of the Tohsun Oasis (Landsat ETM+, 13 August 2010; "gamma correction" was applied to enhance the contrast of this Landsat image). Green identifies arable soils of the Tohsun Oasis, while red and yellow dots represent the locations of soil sampling from grape fields and cotton fields, respectively. The blue line represents the seasonal Bai Yanggou River. The study area of the Tohsun Oasis is approximately $50 \mathrm{~km} \mathrm{SW}$ of the city of Turpan.

emissions obtained by both (bottom-up (biogenic + anthropogenic) and total top-down) approaches.

Please note that in this study we use the term "biogenic emissions" for all kinds of microbiological activities. Here enhanced microbiological emissions caused by agricultural activities are also included. We use the term "anthropogenic emissions" for emissions from combustion.

\section{Materials and methods}

\subsection{Site description and soil sampling}

The study area "Tohsun Oasis" (Fig. 1) is a hyperarid region located in the Xinjiang Uyghur Autonomous Region of China (Mamtimin et al., 2005). The Tohsun Oasis belongs administratively to Turpan County with the city of Turpan as its capital (50 km NE from the Tohsun Oasis). The Tohsun Oasis has an extension of $1479 \mathrm{~km}^{2}$ and a population of 138000 , and topographically it constitutes the deepest point of China (154 m below sea level; $\mathrm{Pu}, 2011)$. Major landform types of the Tohsun Oasis are sandy desert and Gobi Desert (stone desert), surrounded on three sides by the mountains of Bogda (north), Qoeltagh (south), and Alagou (west). Topographically, the Tohsun Oasis slopes down from northwest to southeast. According to the Köppen classification (Kottek et al., 2006), the climate of the Tohsun Oasis is classified as "cold desert", i.e., hot summers (July: $33^{\circ} \mathrm{C}$ ), cold winters (January: $-6^{\circ} \mathrm{C}$ ), and very low precipitation. Mean annual

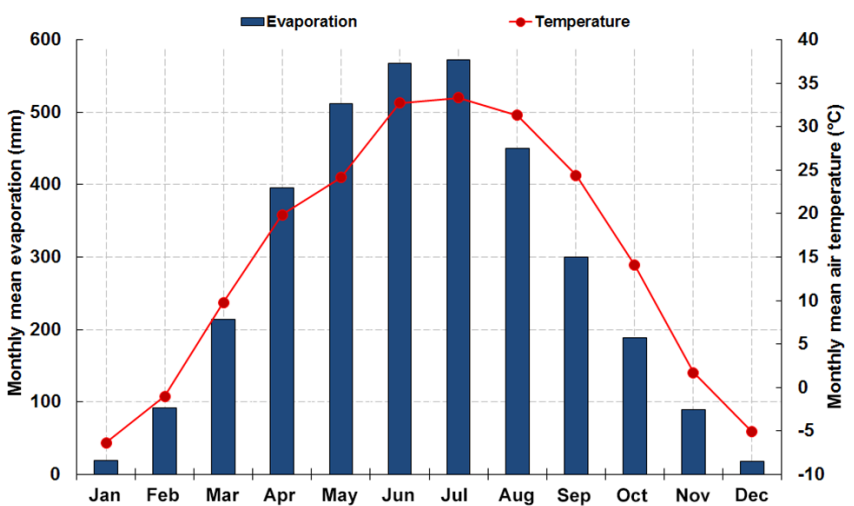

Figure 2. Climate diagram of the Tohsun Oasis. Red dots represent monthly means of air temperature, and blue bars are monthly means of potential evaporation for the period 1971-2005 (data source: Xinjiang Meteorological Bureau, Urumqi, China).

potential evaporation is about $3400 \mathrm{~mm}$ (see Fig. 2), while the mean annual precipitation is as low as $7 \mathrm{~mm}$.

The mean monthly precipitation for Tohsun (not shown in Fig. 2) is extremely low: rainfall in June and July is about $2 \mathrm{~mm}$, while in January, August, and September it is $1 \mathrm{~mm}$; there is no rain for the rest of the year. Agriculture has played and still continues to play a significant role in the Tohsun Oasis; it was one of the most flourishing oases on the ancient Silk Road (Weggel, 1985). Due to the substantial lack of rainfall, regular dryland farming is impossible without massive irrigation. Water supplies for irrigated agriculture are dependent on groundwater (pumping wells), and on the Bai Yanggou River, which originates from the Bogda Mountains. The Bai Yanggou River is temporally, defined by the strong seasonal pattern of snowmelt and rain in the mountains (Mamtimin, 2005).

The Tohsun Oasis's agriculture is dominated by intensive mono-cultivation of grapes and cotton. Grapes from Turpan County are dried naturally into raisins, which are sold on the Chinese internal market and also exported to some Asian countries (Jin and Ma, 2011; Pu, 2011). Grapes from Turpan County account for $52 \%$ of grape production in the Xinjiang Uyghur Autonomous Region, and for $20 \%$ in China as a whole. There, more than 100 small and medium size companies are engaged in raisin processing (Wan, 2012). In 2008, Turpan's raisin production was $130000 \mathrm{t}$, which accounted for more than $90 \%$ of all raisins produced in China (Wan, 2012; Li et al., 2012; Jin and Ma, 2011; Pu, 2009). Approximately $40 \%$ of Turpan's grape production is from the Tohsun Oasis (Pu, 2009). To raise the yields of grapes and cotton, the corresponding cultivation techniques have been optimized, which has resulted in the extensive application of nitrogen-containing fertilizers.

Soil samples from the study area were collected in 2010 from a total of three sites of Tohsun's cotton fields, and from a total of two sites of grape fields (for sample locations, see 
Fig. 1). Since the primary production and consumption zones for NO are located within a very shallow layer at the soil surface ( 1 to $5 \mathrm{~cm}$, e.g., Meixner and Yang, 2006), only soil samples from the first $5 \mathrm{~cm}$ were taken. At each of the sampling sites(randomly from a $10 \mathrm{~m} \times 10 \mathrm{~m}$ area), 10 soil samples (approximately $150 \mathrm{~g}$ ) were taken with stainless steel soil corers ( $5 \mathrm{~cm}$ length, $2.5 \mathrm{~cm}$ radius); these were then combined to constitute a representative soil sample of approximately $1.5 \mathrm{~kg}$ in mass. These soil samples were stored at $4{ }^{\circ} \mathrm{C}$ for a maximum of 3 months until analysis since the microbial alterations are not expected within storage for up to 3 months at $4{ }^{\circ} \mathrm{C}$ (Stotzky et al., 1962). In this study, we also used soil samples from the (non-fertilized) desert ecosystem as the reference, where the desert soil data were adapted from the study of Mamtimin et al. (2015).

\subsection{Remote sensing and accompanying data}

Remote sensing data from both the Landsat and Aura satellites (measurements by the Ozone Monitoring Instrument, OMI) were used in combination with a geographical information system (GIS). Landsat images, provided by United States Geological Survey, are widely applicable for purposes of our study because of their rather high spatial resolution $(30-15 \mathrm{~m})$. Since the aim of our study is the quantification of biogenic NO emissions from intensively managed arid soils, the consideration of the growth state of the corresponding agro-ecosystems is important. For the representation of the different seasons, we selected four individual months: April (spring) for the beginning, July and August (summer) for the middle, and September (autumn) for the end of the vegetation period. The winter season was not considered as most of the agro-ecosystems are frozen. Hence, any microbial activities are negligible. As proposed by many authors (Schott et al., 1985; Markham and Barker, 1986; Irish, 2003; Chander and Markham, 2003), we derived areal distributions of land surface temperature (LST) and land cover types from corresponding satellite data using remote sensing digital image processing. For the selection of Landsat images we confined ourselves to the year 2010, when we took the soil samples. Six individual Landsat images of the Tohsun Oasis (25 April, 28 July, 13 and 21 August, 6 and 22 September 2010) were used.

Tropospheric $\mathrm{NO}_{2}$ column densities derived from OMI (DOMINO version 2.0; Boersma et al., 2011) for the year of 2010 were used for top-down estimates of total $\mathrm{NO}_{x}$ emissions and comparison with total bottom-up emission estimates (biogenic + anthropogenic). The long-term seasonal variability in the tropospheric $\mathrm{NO}_{2}$ was derived from the data of 2006-2010. For the estimation of anthropogenic sources of $\mathrm{NO}_{x}$, we used fossil fuel consumption data from different economic sectors (manufacturing, electricity, transportation, and domestic), which were obtained from the Xinjiang Statistical Yearbooks (Jin and Ma, 2009; Jin and Ma, 2011) and the Turpan Statistical Yearbooks (Pu, 2011). The emission- reduction coefficient for coal-fired thermal power industry was taken from the "China Electric Power Yearbook" (Zhou, 2006). The land use map of Xinjiang $(1: 10000000$; Ma, 2010) and the Traffic Map of Tohsun (1:1050000; Ma, 2010) were used in this study as additional tools for land use classification.

The meteorological data set (1971-2005) of the Tohsun County meteorological station $\left(42.7833^{\circ} \mathrm{N}, 88.6500^{\circ} \mathrm{E}\right.$; $1 \mathrm{~m}$ a.s.l.) was supplied by the Xinjiang Meteorological Bureau. It contains monthly mean (1971-2005) data of air temperature, precipitation, evaporation, wind speed, and direction. Unfortunately, soil moisture content and soil temperature were not measured routinely at Tohsun County Meteorological Station in the time period under consideration. In situ measurements have been performed with a suitable sensor $\left(\mathrm{MSR}^{\circledR} 165\right.$ data logger; Rotronic, Switzerland) which was buried at the site of Tohsun County Meteorological Station at $2.5 \mathrm{~cm}$ depth between July and September 2010. While soil temperature data were measured directly, data of gravimetric soil water content were obtained by gravimetric calibration of the sensor's signal (relative humidity of soil air).

\subsection{Bottom-up calculation of biogenic NO emission estimates}

Estimates of seasonal (monthly) bottom-up biogenic NO emissions for the Tohsun Oasis need (a) laboratory-derived, land-use-type-specific net potential NO fluxes (Sect. 2.3.1); (b) the areal distribution of the three land use types (cotton, grapes, and desert) of the Tohsun Oasis (Sect. 2.3.2); and (c) land-use-type-specific and temporally high-resolution data (Sect. 2.3.3) of soil temperature, gravimetric soil moisture content, and fertilizer (enhancement) factors.

\subsubsection{Laboratory determination of land-use-type-specific net potential NO fluxes}

During the last two decades, the laboratory incubation method has been used to measure the net NO release from soil (Yang and Meixner, 1997; Otter et al., 1999; Kirkman et al., 2001; Feig et al., 2008; Yu et al., 2008; Ashuri, 2009; Gelfand et al., 2009; Bargsten et al., 2010; Behrendt et al., 2014; and Mamtimin et al., 2015). However, today's knowledge of soil biogenic NO emission rates from managed arid soils is still rather limited (cf. Behrendt et al., 2014; Mamtimin et al., 2015; Delon et al., 2015). The laboratory incubation method is usually a dynamic chamber system which consist of gas dilution, a thermostat valve, a thermostat cabinet, and analyzers (Behrendt et al., 2014). The dynamic chamber in this study was made of Plexiglas with a diameter and height of 9.2 and $13.6 \mathrm{~cm}$ (Behrendt et al., 2014), respectively. Five chambers were used for soil samples, while one was kept empty as a reference and the thickness of the sample in the dynamic chamber kept the same (approximately $5 \mathrm{~cm}$ ). The wetted soil samples were placed into five cham- 
bers, while one was kept empty as reference chamber. Then, the net potential NO release rates were measured until the soil was completely dried out. NO fluxes measured in the laboratory by means of the incubation method have repeatedly been shown to be in good agreement with those measured in the field (Mayer et al., 2011; van Dijk et al., 2002; Ludwig et al., 2001). The net release of NO from soil is the result of microbial production and consumption processes which occur simultaneously (Conrad, 1996). In our study, we investigated net $\mathrm{NO}$ releases $\left(J_{\mathrm{NO}}\right.$; in terms of mass of nitrogen per mass of dry soil and time), as well as potential NO fluxes $\left(F_{\mathrm{NO}}\right.$; in terms of mass of atomic nitrogen per area and time) of cotton, grapes, and desert soils. The methodology for the laboratory soil measurements which is used in the frame of this study is described in detail in Behrendt et al. (2014) and Mamtimin et al. (2015). By application of the laboratory dynamic chamber method, the net potential NO flux $F_{\mathrm{NO}}\left(\mathrm{ng} \mathrm{m}^{-2} \mathrm{~s}^{-1}\right.$, in terms of mass of $\mathrm{N}$ ) is defined by

$F_{\mathrm{NO}}\left(\theta_{\mathrm{g}}, T_{\text {soil }}\right)=J_{\mathrm{NO}}\left(\theta_{\mathrm{g}}, T_{\text {soil }}\right) \frac{m_{\text {soil }}}{A}$,

where $J_{\mathrm{NO}}$ (in $\mathrm{ng} \mathrm{kg}^{-1} \mathrm{~s}^{-1}$ ) is derived from the laboratory measurements and $\theta_{\mathrm{g}}$ is the dimensionless gravimetric soil moisture. The soil temperature $T_{\text {soil }}\left(\right.$ in ${ }^{\circ} \mathrm{C}$ ), the total mass of the dry soil sample $m_{\text {soil }}$ (in $\mathrm{kg}$ ), and the cross section of the dynamic chamber $A$ (in $\mathrm{m}^{2}$ ) were directly measured.

Soil moisture and soil temperature had been identified as the most dominant influencing factors of the net NO release; therefore, $J_{\mathrm{NO}}$ is usually parameterized by these two quantities (Yang and Meixner, 1997; Otter et al., 1999; Kirkman et al., 2001; van Dijk et al., 2002; Meixner and Yang, 2006; Yu et al., 2008, 2010; Feig et al., 2008; Ashuri, 2009; Gelfand et al., 2009; Bargsten et al., 2010). While the dependence of $J_{\mathrm{NO}}$ on $T_{\text {soil }}$ is exponential, the dependence of $J_{\mathrm{NO}}$ on $\theta_{\mathrm{g}}$ has the form of an optimum curve. These dependencies are described by two explicit dimensionless functions: the optimum soil moisture curve $g\left(\theta_{\mathrm{g}}\right)$ and the exponential soil temperature curve $h\left(T_{\text {soil }}\right)$, which are described in detail by Behrendt et al. (2014). With $\theta_{\mathrm{g}, 0}$, the optimum gravimetric soil moisture content (i.e., where the maximum $\mathrm{NO}$ release has been observed), introduced and $T_{\text {soil }, 0}=25^{\circ} \mathrm{C}$ as the reference soil temperature, the net potential NO flux, specific for the soils of each land use type $i(i$ : grape fields, cotton fields, desert), is given by

$$
\begin{aligned}
& F_{\mathrm{NO}, i}\left(\theta_{\mathrm{g}, i}, T_{\mathrm{soil}, i}\right)=J_{\mathrm{NO}, i}\left(\theta_{\mathrm{g}, 0, i}, T_{\mathrm{soil}, \mathrm{o}, i}\right) g_{i}\left(\theta_{\mathrm{g}, i}\right) h_{i} \\
& \left(T_{\mathrm{soil}, i}\right) \cdot\left(m_{\mathrm{soil}} / A\right) .
\end{aligned}
$$

The land-use-type-specific exponential soil temperature curve $h\left(T_{\mathrm{soil}, i}\right)$ and the land-use-type-specific optimum soil moisture curve $g\left(\theta_{\mathrm{g}, i}\right)$ are defined by Eqs. (3) and (4):

$$
\begin{aligned}
& h\left(T_{\mathrm{soil}, i}\right)=\exp \left[\frac{\ln Q_{10, \mathrm{NO}, i}}{10}\left(T_{\mathrm{soil}, i}-T_{\mathrm{soil}, 0}\right)\right], \\
& g\left(\theta_{\mathrm{g}, i}\right)=\left(\frac{\theta_{\mathrm{g}, i}}{\theta_{0, i}}\right)^{a} \exp \left[-a\left(\frac{\theta_{\mathrm{g}, i}}{\theta_{0, i}}-1\right)\right] .
\end{aligned}
$$

Land-use-type-specific shape factors " $a$ " of the corresponding optimum soil moisture curves were derived from laboratory drying-out incubation studies on the corresponding soil samples according to Behrendt et al. (2014). The land-use-type-specific quantity $Q_{10, \mathrm{NO}}$ is the (logarithmic) slope of $h\left(T_{\text {soil }}\right)$, which was also derived from the laboratory measurements; with two different soil temperatures applied, $T_{\text {soil }, 0}$ and $T_{\text {soil, } 1}\left(T_{\text {soil, } 1}-T_{\text {soil, } 0}=10 \mathrm{~K}\right)$, the land-use-typespecific $Q_{10, \text { NO }}$ is defined by

$$
Q_{10, \mathrm{NO}}=\frac{\ln F_{\mathrm{NO}}\left(\theta_{g, 0}, T_{\mathrm{soil}, 1}\right)-\ln F_{\mathrm{NO}}\left(\theta_{\mathrm{g}, 0}, T_{\mathrm{soil}, 0}\right)}{T_{\mathrm{soil}, 1}-T_{\mathrm{soil}, 0}} .
$$

\subsubsection{Determination of land use types and corresponding land surface temperatures from Landsat imagery}

We used Landsat images since Landsat provides land surface information in a fine-scale matrix $(30 \mathrm{~m} \times 30 \mathrm{~m})$. The Landsat TM/ETM+ sensors acquire land surface information and store it as a digital number (DN) which ranges between 0 and 255. Landsat images are widely applied for the estimation of biospheric applications, such as the normalized differenced vegetation index (NDVI), land surface temperature (LST), soil moisture index (SMI), and fluxes of matter between different ecosystems (Goward and Williams, 1997; Liang et al., 2002; Lu et al., 2002). To perform land use classification and to derive the corresponding land-use-specific surface soil temperature, we have developed a tool by using ARCGIS 10.x, namely the Geoscience General Tool Package (GGTP; see Supplement, Sects. S1.1-S1.7). Within the GGTP model, we also calculated the 2-D distributions of soil biogenic NO emissions (see Sect. S1.9).

\section{Land use classification}

To classify these field-specific vegetation types, preprocessing of the Landsat imagery and image interpretation has to be performed. To effectively record the image data, histogram equalization and edge detector techniques (Jensen, 2005) were applied to image preprocessing. By using suitable edgedetecting functions, Landsat images were enhanced, and boundaries between different classes were strongly highlighted for effective subsequent image interpretation. Due to the significant requirements for the different areas of interests (AOIs) of image classification, in situ GPS data (160 points) from the field campaigns (2010) as well as previous field investigations $(2006,2008)$ were used. Spectral signatures of in situ data were collected by digitizing and were consequently 
used to classify all pixels. For that, image spectral analysis and the most used supervised classification method of maximum likelihood by Jensen (2005) was performed. This procedure ensured that (a) spectral characteristics of all AOIs were used and (b) every pixel (both within and outside AOIs) was assessed and associated with the land cover which it has the highest likelihood of being a member.

\section{Land surface temperature $T_{\mathrm{s}}$}

Knowledge of the land surface emissivity $(\varepsilon)$ is indispensable for retrieving the land surface temperature $\left(T_{\mathrm{S}}\right)$ from remotely sensed data. As the land cover varies greatly from place to place, land surface emissivity widely varies from one location to another. Therefore, the land surface temperature $T_{\mathrm{S}}$ is defined as

$T_{\mathrm{S}}=\frac{1}{\varepsilon^{0,25}} T_{\mathrm{B}}$.

The land surface emissivity $(\varepsilon)$ can be obtained from red and near-infrared (NIR) spectral reflectance, while at-sensor brightness temperature $\left(T_{\mathrm{B}}\right)$ can be calculated from the satellite image's thermal band in high-gain mode (band 6.2); more details are given in the Supplement (Sects. S1.2-S1.6).

\subsubsection{Temporally high-resolution data}

Bottom-up calculations in this study aim for regional, seasonal (monthly), and land-use-specific soil biogenic NO emissions via laboratory-derived net potential NO fluxes, which depend on soil temperature, gravimetric soil moisture (Sect. 2.3.1), and fertilizer factors (i.e., amplification of NO fluxes due to the application of fertilizer). However, the necessary timescale for these data must be much shorter than a seasonal (monthly) timescale: (a) there is a strong nonlinear response of the net potential NO flux to soil temperature and gravimetric soil moisture (Eqs. 3, 4), as well as to fertilizer applications, and (b) there are large diel variations in the topsoil temperature (e.g., $10-60^{\circ} \mathrm{C}$ in July; Tohsun Oasis desert soil) and large diel to weekly variations in soil moisture and soil nutrient content caused by the applied irrigation and fertilization schedules. Consequently, seasonal (monthly) land-use-type-specific soil NO emissions have to be averaged from data calculated on much shorter timescales $(<1 \mathrm{~h})$.

\section{Soil temperature, $T_{\text {soil }}$}

Due to the very low soil temperature before and after the growing season (see Fig. 1b), most of the soil surface is expected to be frozen, and biogenic emissions from any soils of the Tohsun Oasis can be neglected. Thus, mean monthly soil NO emissions were only calculated for the period between April to September. In situ measurements of soil temperature (and soil moisture; $2.5 \mathrm{~cm}$ depth, $5 \mathrm{~min}$ resolution) at the Tohsun Oasis have only been performed for the land use type "desert", and only for the period 1 July to 30 September 2010 (see Sect. 2.2). However, soil temperature (and soil moisture; $2.5 \mathrm{~cm}$ depth, $5 \mathrm{~min}$ resolution) have also been measured at two other Taklimakan oases during the same period, namely at Kuche $\left(41.5360^{\circ} \mathrm{N}, 82.8546^{\circ} \mathrm{E}\right.$; "cotton soils") and Minfeng (37.0534 ${ }^{\circ} \mathrm{N} ; 82.0760^{\circ} \mathrm{E}$; "jujube soils"). For this study, data from Kuche were adopted for the land use type "cotton soils" of the Tohsun Oasis, while data from Minfeng were chosen to substitute grape soils data of the Tohsun Oasis. The latter is justified by the fact that both grapes and jujube belong to the bushy agricultural landscape type; they have similar height, distance in rows, water requirements, and percent ground cover by their canopy. For each of the three land use type data sets, each original measured data point (5 min, July-September, 2010) of a particular day has been normalized by the mean value observed at 10:45 LT (Landsat satellite overflight, Supplement Fig. S7). Then, a mean diel variation data set $(30 \mathrm{~min})$ was created by averaging all respective data between 1 July and 30 September constituting the representative diel variation in the (normalized) soil temperature of the respective land use type valid for the entire growing period (Supplement Sect. S3.1; Fig. S8). As described in Sect. S3.1 of the Supplement, land-use-typespecific surface temperatures $\left(T_{\mathrm{S}}\right.$; Sect. 2.3.2) derived from Landsat observations on 25 April, 28 July, 13 and 21 August, and 6 and 22 September 2010 (Sect. 2.2) have been temporally upscaled for the entire growing season (1 April30 September 2010). Finally, the diel variation in soil temperatures of the land use types "desert", "cotton soils", and "grape soils" for every day of the growing season in 2010 was obtained by multiplying the normalized soil temperatures.

The interpolation of the satellite-derived data was done by a third-order polynomial. To estimate the corresponding uncertainties, we compared results using polynomials of degree 2 and 3 for the fitted curve. We found that $R^{2}$ in the seconddegree model was $89 \%$, while in the third-degree model it is $98 \%$.

\section{Gravimetric soil moisture $\boldsymbol{\theta}_{\mathrm{g}}$}

Evaluation of the MSR ${ }^{\circledR} 165$ data logger measurements (see Sect. 2.2) at the site of the Tohsun County meteorological station (bare desert soil) has demonstrated a temporally quite constant, very low gravimetric soil moisture content of 0.0028 , which has been adapted for the entire growing season (April-September 2010) land use type "desert" of the Tohsun Oasis. Temporal variation in gravimetric soil moisture content of the two other land use types, cotton soils and grape soils, depends strongly on irrigation amounts and schedules. Unfortunately, there is no official information on the Tohsun Oasis's irrigation available, neither on amounts nor schedules, and, consequently, none on the gravimetric soil moisture contents during the drying-out phases between individual irrigation events. Therefore, as for data assimilation of soil temperatures (see above), gravimetric soil mois- 
ture content data observed at Taklimakan's oases Minfeng (cotton soils) and Kuche (jujube soils) have been adapted for the Tohsun Oasis's land use types "grape soils" and "cotton soils", respectively. The irrigation farming consists of temporally constant irrigation schedules, starting on 1 April 2010 and repeated every 2 weeks. From the observations at Minfeng and Kuche, "drying-out" shape functions could be defined, which were scaled by multiples of the soil-specific physical quantity "field capacity" (FC), the amount of water content held in the soil after excess (irrigation) water has drained away. The quantity FC is typically used in irrigation scheduling, calculation of plant available water, and calculation of water depth to be applied by irrigation (Diallo and Mariko, 2013). FC data of soil samples from Minfeng and Kuche oases have been determined by laboratory measurements (see Sect. S1.8, Supplement). Finally, for the Tohsun Oasis's land use types, cotton soils and grape soils, the following gravimetric soil moisture contents have been chosen (for details, see Sect. S3.2, Supplement): (a) 0.086 (grape soils) and 0.167 (cotton soils) before the first irrigation event (corresponding to mean gravimetric soil moisture contents at conditions of $0.25 \times \mathrm{FC}$ and $0.5 \times \mathrm{FC}$, respectively) and (b) 0.514 (grape soils) and 0.586 (cotton soils) after each irrigation (corresponding to mean gravimetric soil moisture contents at conditions of $1.5 \times \mathrm{FC}$ and $1.75 \times \mathrm{FC}$, respectively). Since for each irrigation event (every 14 days) the starting and end conditions in terms of gravimetric soil moisture content were known, as well as the functional relationship for the temporal drying-out of cotton soils and grape soils between the irrigation events, temporally highresolution data $(30 \mathrm{~min})$ could be calculated. The result, the seasonal variation (1 April 2010 (DOY 90)-30 September 2010 (DOY 273)) of the gravimetric soil moisture content (at $30 \mathrm{~min}$ resolution) for the land use types "cotton fields" and "grape fields" of the Tohsun Oasis is illustrated in Fig. S9 (Supplement).

\section{Fertilizer factor (FF)}

To maintain the productivity of the grape and cotton fields of the Tohsun Oasis, the soils regularly receive considerable $\mathrm{N}$-containing fertilizer amounts (see Sect. 2.1). The impact of the fertilizer application on the NO fluxes from arable soils of Taklimakan oases was recently investigated by Fechner (2014) using the laboratory dynamic chamber system described by Behrendt et al. (2014). Depending on the applied fertilizer amount (FA), NO fluxes from all soil samples increased considerably and immediately after fertilizer application, which was accomplished by dissolving the mineral fertilizer in the same amount of water that was used to wet the soil samples (just to mirror the fertilization procedures of the Taklimakan oases). The impact of fertilization is twofold: (a) it strongly amplifies the net release (net potential flux) of NO over the entire range of gravimetric soil moisture and (b) there is a moderate amplification of the net NO release (net NO potential flux) with soil temperature. Furthermore, the impact of fertilization also has a temporal dimension: it has been shown that the fertilizer effect on the emission of N-containing gasses is temporally declining after each fertilization event (Chen et al., 2011). Therefore, the fertilizer effect may be considered (a) by the multiplicative, FAdependent, time-dependent, dimensionless "fertilizer factor" (FF) applied to the standard net release $J_{\mathrm{NO}}\left(\theta_{\mathrm{g}, 0}, T_{\mathrm{soil}, 0}\right)$ in Eq. (2) and (b) by the FA-dependent, time-dependent, dimensionless " $Q_{10}$ factor" $\left(Q_{10} F\right)$, which is also multiplicatively applied to $Q_{10}$ (the logarithmic slope of the exponential soil temperature curve $\left.h\left(T_{\text {soil }}\right)\right)$. According to Fechner (2014), initial fertilizer effects are $\mathrm{FF}=142,179,205$, and 226 and $Q_{10} F=1.21,1.24,1.25$, and 1.26 for fertilization amounts $\mathrm{FA}=100,200,300$, and $400 \mathrm{~kg}(\mathrm{~N}) \mathrm{ha}^{-1}$, respectively. From recommendations of the Tohsun Oasis's local agricultural administration (personal communication, 2010) and our interviews with farmers there in 2010 , data for applied fertilizer amounts as well as for fertilizing schedules could be inferred. With the assumption of an exponential decay of the fertilizer effects, corresponding functional relationships for the temporal behaviors of $\mathrm{FF}$ and $Q_{10} F$ have been developed (see Sect. S3.3, Supplement), and temporally high-resolution data (30 min) of FF and $Q_{10} F$ were calculated. The result - i.e., the seasonal variation (1 April 2010 (DOY 90)-30 September 2010 (DOY 273)) in the (dimensionless) factors FF and $Q_{10} F$ for the land use types "cotton fields" and "grape fields" of the Tohsun Oasis - is illustrated in Fig. S10 (Supplement).

\subsubsection{Monthly soil biogenic NO and HONO bottom-up emissions of the Tohsun Oasis}

Estimates of soil biogenic NO fluxes can be calculated from net potential NO fluxes (see Sect. 2.3.1) according to Eqs. (1)-(4), since those NO fluxes that are derived from laboratory incubations have repeatedly been shown to be in good agreement with those measured in the field (Mayer et al., 2011; van Dijk et al., 2002; Ludwig et al., 2001). Consequently, soil biogenic NO fluxes for the Tohsun Oasis were calculated every $30 \mathrm{~min}$ from land-use-specific net potential NO fluxes (see Sect. 2.3.1) using land-use-specific data of soil temperature (see Sect. 2.3.3), gravimetric soil moisture contents (see Sect. 2.3.3), and fertilizer factors (see Sect. 2.3.3). Bottom-up soil biogenic NO emissions for the entire region of the Tohsun Oasis were calculated monthly by (a) averaging temporally high-resolution data (30 min) of the three land-use-specific soil biogenic net NO fluxes for each month of the growing period (April-September 2010), (b) weighting by the areal contribution of each of the three land use types $\left(1117,80\right.$, and $150 \mathrm{~km}^{2}$ for desert, grape, and cotton soils; see Sect. 2.3.2), and (c) summing up for each month of 2010 .

The soil temperature is usually the dominating factor of the uncertainties of NO fluxes because of the exponential dependence of the NO flux on soil temperature (typically 
expressed as the increase in the NO flux for a $10^{\circ} \mathrm{C}$ increase in soil temperature known as a $Q_{10}$; see Sect. 2.3.1). The mean $Q_{10}$ value is 2 for both cotton and grape soils. The total uncertainties of bottom-up NO emissions were determined from (a) the errors of the concentration measurements of NO, which was conservatively assumed to be $5 \%$ (Behrendt et al., 2014), and (b) errors of the simulated soil temperatures, which were assumed to be $1.5-2.5^{\circ} \mathrm{C}$ in both estimates (satellite-derived (see Fig. S4) and estimated land surface temperatures (see Fig. S7)).

The studies by Su et al. (2011) and Oswald et al. (2013) pointed out that the HONO and NO emissions have to feature similar dependencies on soil properties, and there exists a co-emission of HONO with NO from the soil; therefore, it could be expected that the HONO and NO emission processes follow similar parameters (Naegele and Conrad, 1990; Skopp et al., 1990, Gödde and Conrad, 2000; Oswald et al., 2013).

The recent findings of Oswald et al. (2013), namely that a large amount of gaseous nitrous acid (HONO) is concurrently emitted along with NO, have been considered for the monthly estimation of biogenic emissions of the Tohsun Oasis. The authors investigated a total of 17 soil samples, which were taken from a variety of natural and agriculturally managed soils around the globe. Fortunately, five of these samples (no. S13-S17 in Oswald et al., 2013) were cotton, jujube, and desert soils of the Taklimakan region; they have the same arid climate condition and irrigation regime as well as fertilizer application as those used for this study. The strong dependency of HONO emissions on soil water content and soil properties was determined by laboratory experiments with dynamic chamber systems (Oswald et al., 2013). Since the HONO emissions were not directly measured within the present study, the land-use-specific constant scale factor - namely the ratios of HONO to NO releases for the optimum conditions to estimate the HONO emissions $\left(\left(F_{\mathrm{N}}\right.\right.$, opt $(\mathrm{HONO})$ to $\left.F_{\mathrm{N}_{\mathrm{opt}}}(\mathrm{NO})\right)$ - were adapted from the study of Oswald et al. (2013). This is justified by (a) the strong assumption that the soil from our study emits the same magnitude of HONO as the soil by Oswald et al. (2013) because they have the same soil properties and experienced the same irrigation regimes and fertilizer applications, and (b) the soil release of HONO and NO by Oswald et al. (2013) has also been measured in the Max Planck Institute for Chemistry by a next-laboratory version of the dynamic chamber system which was used to measure the soil release of NO in the present study. Consequently, corresponding ratios for the optimum conditions of $\mathrm{HONO}$ and $\mathrm{NO}$ emissions (i.e., $F_{\mathrm{N} \text {, opt }}(\mathrm{HONO})$ to $F_{\mathrm{N}_{\text {,opt }}}(\mathrm{NO})$ ) have been used to calculate monthly HONO emissions from the Tohsun Oasis from the measured NO emissions. Monthly land-use-type-specific contributions of $\mathrm{HONO}$ emissions for the Tohsun Oasis during the growing period 2010 were estimated by multiplying the corresponding $\mathrm{NO}$ emissions by the mean, land-use-type-specific factors $(0.8$ for grape and desert soils, and 1.6 for cotton soils). These were calculated from individual values provided by Oswald et al. (2013), which are derived from the ratio for the optimum condition $F_{\mathrm{N} \text {,opt }}(\mathrm{HONO})$ to $F_{\mathrm{N}_{\text {,opt }}}(\mathrm{NO})$. To quantify the uncertainties of calculated HONO emissions, the mean relative errors for concentration measurements of $12 \%$ for HONO (Sörgel et al., 2011) and $5 \%$ for NO (Behrendt et al., 2014) were adopted. Based on these estimates, we performed a conservative error propagation calculation of the additional HONO emissions (under optimum conditions), which resulted in a relative error of $10 \%$.

In the present study, the total bottom-up biogenic emission estimates (NO and HONO) were expressed in terms of mass of atomic nitrogen - partly because the reported mass of emitted nitrogen compounds becomes independent of the partitioning ratio between $\mathrm{NO}$ and $\mathrm{NO}_{2}$. Additionally, the anthropogenic and top-down emissions estimates are primarily derived for $\mathrm{NO}_{2}$. In this study, the mean primary $\mathrm{NO}_{2}$ emissions were not considered, and all $\mathrm{NO}_{x}$ emissions are being reported as the mass of nitrogen. For that purpose soil biogenic emissions of NO and HONO (given as mass) were multiplied by the respective ratios of the corresponding molecular weights $\left(M_{\mathrm{N}} / M_{\mathrm{NO}}, M_{\mathrm{N}} / M_{\mathrm{HONO}}\right)$.

For the comparison of biogenic bottom-up emissions $\left(F_{\text {biogenic }}\right)$ with top-down emissions $\left(F_{\text {satellite }}\right)$ only the data around the time of the satellite overpass around 13:00 LT were considered (bottom-up results for 12:45 LT (12:3013:00) and 13:15 LT (13:00-13:30)). To estimate the effect of the diurnal cycle of the emissions, we calculated the ratio of the bottom-up emission at the satellite overpass (at 13:00 LT) and the daily average emissions.

\subsection{Bottom-up anthropogenic $\mathrm{NO}_{x}$ emission estimates}

The Tohsun Oasis's anthropogenic $\mathrm{NO}_{x}$ emissions predominantly originate from fossil fuel combustion of the energy and traffic sectors. To quantify the amount of an emitted substance from a source like fossil fuel consumption, specific emission factors have to be applied, which are expressed as the fraction of the substance emitted from the mass or volume of the fuel. In China, emission factors for different economic sectors and fuel types are available but are quite variable during the last decade. Based on sparsely available statistical data, the fuel types consumed in Tohsun range from coal to coke, crude oil, natural gas, diesel, and gasoline. For the calculation of bottom-up anthropogenic $\mathrm{NO}_{x}$ emissions, we used those $\mathrm{NO}_{x}$ emission factors (mass of emitted $\mathrm{NO}_{x}$ per mass of fuel, weighted as $\mathrm{NO}_{2}$ ) which are widely used in China (see Table S1; Supplement). Following Hao et al. (2002), Zhang et al. (2009), and Shi et al. (2014) an algorithm (see Eq. S13, Supplement) has been applied to calculate the emitted mass $\left(E^{\mathrm{N}}\right.$; in $\left.\mathrm{kg} \mathrm{NO}_{2}\right)$ from emission factors $K^{\mathrm{N}}$ (in $\mathrm{kg} \mathrm{t}^{-1}$ ), dimensionless removal efficiencies $P^{\mathrm{N}}$ of corresponding emission-reduction technology, and the particular fuel consumption $F$ (in t). Unfortunately, data on 
fossil fuel consumption from the different economic sectors of Tohsun County (see Sect. 2.2) are only available on an annual basis. Mean monthly data of the Tohsun Oasis have been assimilated (downscaled) by multiplicative consideration of known mean monthly percentages of annual $\mathrm{NO}_{2}$ emissions of Urumqi ( $140 \mathrm{~km}$ NNW of Tohsun). This is justified by (a) coal being the dominating fuel type of energy consumption in both areas (Mamtimin and Meixner, 2011; $\mathrm{Pu}, 2011$ ), (b) identical arid climate conditions (resulting in identical heating periods), and (c) there being known mean monthly percentages of annual $\mathrm{NO}_{2}$ emissions only from Urumqi. More details are given in Sect. S3.3 of the Supplement. Monthly anthropogenic emission estimates expressed in terms of mass of atomic nitrogen because these have to be comparable to the biogenic ones.

\subsection{Top-down total $\mathrm{NO}_{x}$ emission estimates from satellite observations}

The satellite-retrieved tropospheric vertical column densities of $\mathrm{NO}_{2}\left(\mathrm{VCD}_{\mathrm{NO}_{2}}\right)$ over the Tohsun Oasis can provide information for a daily measure of the atmospheric $\mathrm{NO}_{2}$ concentration vertically integrated over the entire troposphere (during the time of overflight, around 13:00 LT). Only a few assumptions are necessary to derive related $\mathrm{NO}_{2}$ fluxes (representing total $\mathrm{NO}_{x}$ emissions) from these data: (1) the $\mathrm{NO}_{2}$ molecules of the tropospheric vertical column originate exclusively from $\mathrm{NO}_{x}$ emissions (anthropogenic + biogenic) from the area of the Tohsun Oasis; (2) due to the surface source, the abundance of $\mathrm{NO}_{2}$ molecules of the tropospheric vertical column is within its lowermost part, the atmospheric boundary layer; (3) the depletion of $\mathrm{NO}_{x}$ in the atmospheric boundary layer is primarily due to the reaction of $\mathrm{NO}_{x}$ with the hydroxyl radical $\mathrm{OH}$ (leading to the formation of gaseous nitric acid, $\mathrm{HNO}_{3}$ ); and (4) the chemical lifetime of the $\mathrm{NO}_{x}$ is approximately known.

\subsubsection{Satellite-derived tropospheric $\mathrm{VCD}_{\mathrm{NO}_{2}}$}

OMI satellite data of tropospheric $\mathrm{NO}_{2}$ were chosen because of their smaller pixel size $(13 \mathrm{~km} \times 24 \mathrm{~km}$ in nadir $)$ compared to data from SCIAMACHY $(60 \mathrm{~km} \times 30 \mathrm{~km})$ or GOME $(320 \mathrm{~km} \times 40 \mathrm{~km})$. OMI is operated in a Sun-synchronous orbit such that measurements are taken at about 13:00 LT. OMI data also provide daily global coverage (Boersma et al., 2007). For our study, we used the OMI monthly mean tropospheric $\mathrm{NO}_{2}$ data, which are calculated on the basis of the results of daily OMI overflights (around noon) and are provided by TEMIS (Tropospheric Emission Monitoring Internet Service, European Space Agency (ESA); http: //www.temis.nl/). The OMI monthly mean tropospheric $\mathrm{NO}_{2}$ data product was averaged on a $0.125^{\circ} \times 0.125^{\circ}$ grid and has been retrieved for cloud fractions $<20 \%$.

It should be noted that the tropospheric VCDs derived from satellite measurements can be systematically affected by the a priori assumptions needed for the calculation of the air mass factor (AMF; reflecting the satellite sensitivity for tropospheric $\mathrm{NO}_{2}$ ), such as cloud fraction, pressure at cloud level, surface albedo, and trace gas profile (Boersma et al., 2007, 2011). Fortunately, the region of Tohsun County provides relatively favorable conditions for accurate calculation of tropospheric AMFs, since the desert region is typically only slightly affected by clouds and aerosols; also, lightning activity, due to the predominant absence of convective rains, is rather weak, if not negligible. The $\mathrm{AMF}$ for $\mathrm{OMI}$ DOMINO v2.0 has been calculated using TM4 model $\mathrm{NO}_{2}$ profiles with a longitude-latitude resolution of $3^{\circ} \times 2^{\circ}$, a surface reflectance climatology $\left(0.5^{\circ} \times 0.5^{\circ}\right)$, and cloud information (Boersma et al., 2011). To test whether the assumed surface albedo is appropriate for the Tohsun Oasis, we examined the OMI surface reflectance climatology for the study area and compared it with the high-resolution MODIS surface reflectance product $\left(0.05 \times 0.05^{\circ}\right.$, MOD43B $)$. We used the MODIS albedo products from channel 3 (at 459-479 nm) because this channel is close to the spectral window (405$465 \mathrm{~nm}$ ) used for the OMI retrieval. According to Kleipool et al. (2008), the surface albedo difference between $470 \mathrm{~nm}$ (center of MODIS channel) and $440 \mathrm{~nm}$ (OMI surface reflectance climatology) is very small for land surfaces.

To account for any background $\mathrm{NO}_{2}$ from upwind (desert) areas, representative $\mathrm{VCD}_{\mathrm{NO}_{2}}$ observed over the Taklimakan Desert $\left(400 \mathrm{~km}\right.$ away from the oasis, at $85.5129^{\circ} \mathrm{E}$, $40.0669^{\circ} \mathrm{N}$ ) were subtracted from the $\mathrm{VCD}_{\mathrm{NO}_{2}}$ observed over the Tohsun area.

To check the representativeness of satellite-derived $\mathrm{NO}_{2}$ on the regional scale, we investigated the interannual variability in tropospheric $\mathrm{VCD}_{\mathrm{NO}_{2}}$ from 2006 to 2010. This is because a mean value of longer periods leads to significantly reduced uncertainties, and it can better demonstrate the representativeness of satellite-derived $\mathrm{NO}_{2}$. Evidence of a clear seasonal pattern in the long-term observations can reflect the true seasonal effect on tropospheric $\mathrm{VCD}_{\mathrm{NO}_{2}}$, which is of substantial importance with respect to the intended comparison of "bottom-up" vs. "top-down". Seasonal patterns (i.e., December-February, March-May, June-August, September-November) of satellite-derived $\mathrm{NO}_{2}$ column densities were evaluated using long-term cloud-free (cloud fraction $<20 \%$ ) measurements from 2006 to 2010 .

Satellite observations reflect contributions from different emission sources. In principle, the retrieval of $\mathrm{NO}_{2}$ emissions over a city or oases is similar. However, usually the emissions from cities are higher, and the corresponding enhancements can be better identified compared to the background. In order to establish the relationship between biogenic $\mathrm{NO}_{2}$ and satellite-derived $\mathrm{NO}_{2}$, it is necessary to understand their spatial patterns with respect to the locations and shapes of the potential sources. Thus, four different areas (see Fig. 3) were selected to represent (1) typical agricultural areas (study area) as the biogenic source, (2) mixed land use areas (agricultural and small urban) as the biogenic and anthropogenic 


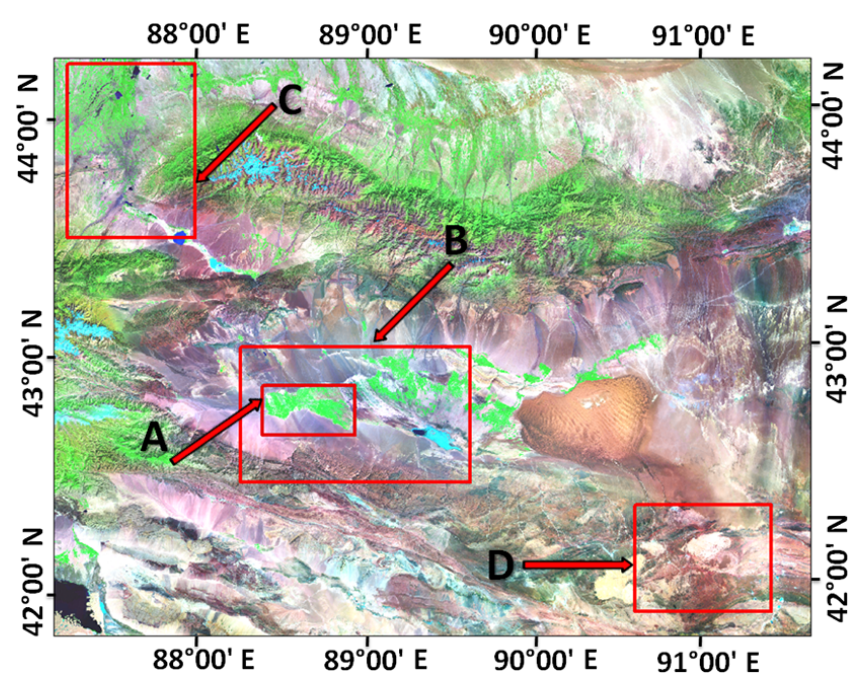

Figure 3. Selected areas for the examination of the spatial seasonal variation in the tropospheric $\mathrm{NO}_{2}$ VCDs: rectangles "A", "B", "C", and " $\mathrm{D}$ " represent an agricultural area (Tohsun), a mixed land use area (Tohsun and Turpan), a large urban area (Urumqi), and a desert area, respectively.

sources, (3) large urban areas as the anthropogenic source, and (4) desert area as the background source.

\subsubsection{Monthly total $\mathrm{NO}_{x}$ emissions of the Tohsun Oasis (top-down)}

For the top-down inventory, the given molecular weight of $\mathrm{NO}_{2}$, Avogadro's number, a lifetime of $\mathrm{NO}_{x}$, and pixel area $\left(\mathrm{m}^{2}\right)$ of $\mathrm{NO}_{2}$ were considered. Top-down $\mathrm{NO}_{x}$ emissions from the Tohsun Oasis were calculated from all $\mathrm{VCD}_{\mathrm{NO}_{2}}$ - whose pixels cover the area of the Tohsun Oasis and where each represents the particular monthly mean of 2010 - as follows: (a) from each individual $\mathrm{VCD}_{\mathrm{NO}_{2}}$ (in $\mathrm{NO}_{2}$ molecules $\mathrm{cm}^{-2}$ ) the representative "desert" $\mathrm{VCD}_{\mathrm{NO}_{2}}$ value was subtracted to account for any background $\mathrm{NO}_{2}$ from upwind (desert) areas; (b) all of these $\mathrm{VCD}_{\mathrm{NO}_{2}}$ were multiplied by their respective pixel area and summed up to obtain the mean number of (vertically integrated) $\mathrm{NO}_{2}$ molecules for each month of 2010 over the Tohsun Oasis (for the area indicated in Fig. 3); (c) this value was converted to mass of $\mathrm{NO}_{2}$ per unit area $\left(\mathrm{m}^{2}\right)$ and divided by the characteristic lifetime of $\mathrm{NO}_{x}, \tau_{\mathrm{NO}_{x}}$ (with respect to its reaction with the hydroxyl radical $\mathrm{OH}$ ); and (d) in order to compare the top-down and bottom-up emission estimates, the monthly mean top-down emissions and their daily averages were expressed in terms of mass of atomic nitrogen.

The corresponding result represents the monthly mean total $\mathrm{NO}_{x}$ emission (i.e., from anthropogenic and biogenic sources) from the area of the Tohsun Oasis at the time of the OMI satellite overflight (and a few hours before). Here, it should be noted that meteorological information does not have to be taken into account explicitly because, from the satellite observations (Fig. 9), we can conclude that most of the $\mathrm{NO}_{x}$ (about more than $90 \%$ ) is destroyed before it is blown outside the considered area by wind. The characteristic lifetime of $\mathrm{NO}_{x}$ can be expressed as a short lifetime. It has been investigated by Beirle et al. (2011), for example, and can be estimated at about $\tau_{\mathrm{NO}_{2}}=4 \mathrm{~h}$ for low and mid-latitudes, particularly for the dryland cities of Isfahan $\left(32.6^{\circ} \mathrm{N}\right)$ and Riyadh $\left(24.6^{\circ} \mathrm{N}\right)$.

\section{Results and discussion}

\subsection{Bottom-up soil biogenic and anthropogenic emissions from the Tohsun Oasis}

\subsubsection{Laboratory-derived net potential NO fluxes}

Results of the laboratory-derived net potential NO fluxes $\left(F_{\mathrm{NO}}\right)$ from soils of the desert and the irrigated and fertilized cotton and grape fields are shown in Fig. 4. The highest mean net potential NO flux at $25^{\circ} \mathrm{C}$ occurred from the cotton soils, with a maximum net potential NO flux of $57.5 \mathrm{ng} \mathrm{m}^{-2} \mathrm{~s}^{-1}$ followed by grape soils $\left(18.9 \mathrm{ng} \mathrm{m}^{-2} \mathrm{~s}^{-1}\right)$ and desert soils (4.1 $\mathrm{ng} \mathrm{m}^{-2} \mathrm{~s}^{-1}$ ). Common to all net potential NO fluxes from the major land use types of the Tohsun Oasis is the exponential response to soil temperature, due to strong enzymatic activities associated with microbial processes of soil NO production. During the growing period (April to September), soil temperatures of $45^{\circ} \mathrm{C}$ plus are easily reached in the soils of the Tohsun Oasis, particularly for the desert soils (see Supplement, Fig. S1). At $T_{\text {soil }}=50^{\circ} \mathrm{C}$, the maximum net potential NO fluxes of 384 (cotton soils), 115 (grape soils), and $46 \mathrm{ng} \mathrm{m}^{-2} \mathrm{~s}^{-1}$ (desert soils) are reached at an optimum gravimetric soil moisture content $\left(\theta_{\mathrm{g}, \mathrm{opt}}\right)$ of $0.021,0.146$, and 0.0158 , respectively. These $\theta_{\mathrm{g}, \text { opt }}$ values, particularly those of the cotton and desert soils, are much lower than those of natural and agricultural soils of temperate latitudes ( $>0.25$; cf. Oswald et al., 2013; Behrendt et al., 2014).

To emphasize this, significant net potential NO fluxes from desert soil only occurs if $\theta_{\mathrm{g}}$ is higher than 0.01 and less than 0.03 . Since the observed $\theta_{\mathrm{g}}$ value of the Tohsun desert soils is 0.0028 (see Sect. 2.3.3), no significant biogenic NO emissions are expected from there. As stated in Sect. 2.3.3, the chosen irrigation schedules of cotton and grape fields resulted in certain, predefined ranges of gravimetric soil moisture content (depending on the field capacity (FC) of the respective soils). Immediately after each irrigation event, $\theta_{\mathrm{g}}$ values of 0.514 (grape soils) and 0.586 (cotton soils) occur; according to Fig. 4, there will be no significant biogenic NO emissions at this stage. However, after 14 days (just before the next irrigation event), $\theta_{\mathrm{g}}$ values as low as 0.086 (grape soils) and 0.167 (cotton soils) are found; consequently, regarding the results in Fig. 4, maximum biogenic NO emissions from grape soils have to be expected for the end of the 14-day irrigation period $\left(\theta_{\mathrm{g}, \mathrm{opt}}=0.146\right)$, while at that 

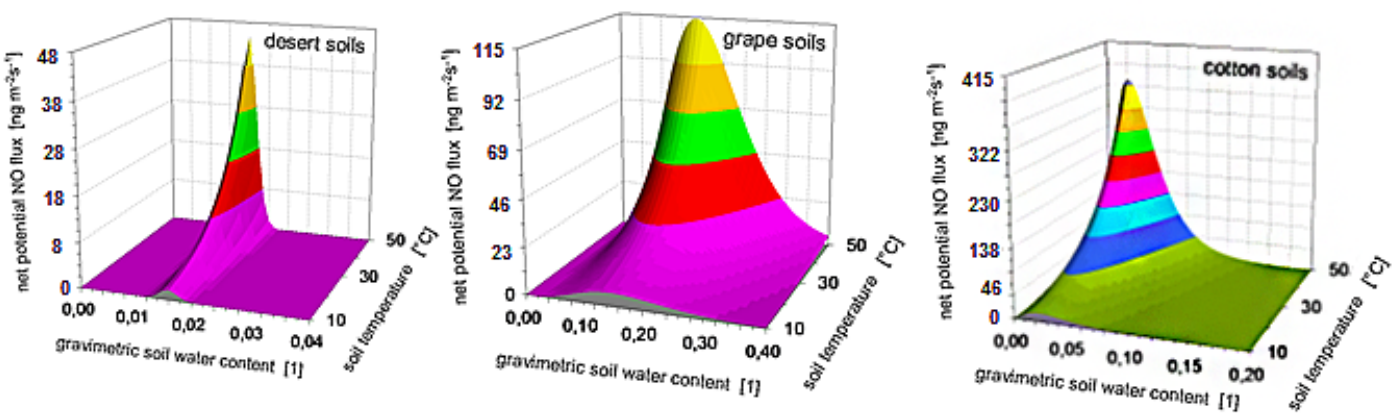

Figure 4. Results of laboratory incubation measurements on soil samples of the Tohsun Oasis taken in 2010: the net potential NO fluxes $F_{\mathrm{NO}}\left(\mathrm{ng} \mathrm{m}^{-2} \mathrm{~s}^{-1}\right.$, in terms of mass of $\left.\mathrm{N}\right)$ from the three major land use types of the Tohsun Oasis (desert, grape, and cotton soils) are shown as functions of soil temperature and the gravimetric soil moisture content. The soil samples were taken in 2010. Note the different scales of net potential NO fluxes and the gravimetric soil water content.

time, biogenic $\mathrm{NO}$ emissions from cotton soils will be (even at $T_{\text {soil }}=50^{\circ} \mathrm{C}$ ) less than $4.6 \mathrm{ng} \mathrm{m}^{-2} \mathrm{~s}^{-1}$ since then the $\theta_{\mathrm{g}}$ value for cotton soils (0.167) is far above the corresponding optimum value $\left(\theta_{\mathrm{g}, \mathrm{opt}}=0.021\right)$. This means that despite the overwhelming potential of cotton soils to dominate the biogenic NO emissions of the Tohsun Oasis (see Fig. 4), their net actual contribution is almost negligible over the full 14day irrigation cycle (see below). It should be noted that for other oases - with other irrigation cycles - the contribution to cotton soils might be much larger.

\subsubsection{Land-use-type-specific net NO fluxes based on soil temperature, soil moisture content, and enhancement by fertilizer application}

The land cover classification of the Tohsun Oasis has also been derived from Landsat images. Based on these results, the dominant land cover types were cotton and grapes, building/residential areas, other vegetation, and desert (see Fig. 5).

Biogenic net NO fluxes (in $\mathrm{ng} \mathrm{m}^{-2} \mathrm{~s}^{-1}$, in terms of NO) from the three land use types of the Tohsun Oasis have been calculated from laboratory-derived, land-use-specific net potential NO fluxes (see above) by Eqs. (2)-(5) from assimilated data sets of soil temperature, gravimetric soil moisture content, and the enhancement of biogenic net NO fluxes caused by regular fertilizer application (see Sect. 2.3.3).

Three-dimensional graphs of the seasonal variation (1 April 2010 (DOY 90)-30 September 2010 (DOY 273)) in the mean diel soil temperature (at $30 \mathrm{~min}$ resolution) are presented in Fig. 6 for desert, grape, and cotton soils of the Tohsun Oasis. As expected, soil temperature in desert soils exhibits the largest variation on both diel and seasonal scales, while - due to the shading by the considerably dense canopy of cotton plants - the corresponding variations in the soil temperature in cotton fields are smallest. The corresponding seasonal variations in the gravimetric soil moisture content, as well as the (dimensionless) fertilizer factors $\mathrm{FF}$ and $Q_{10} F$ (at 30 min resolution) for the Tohsun Oasis's cotton and grape

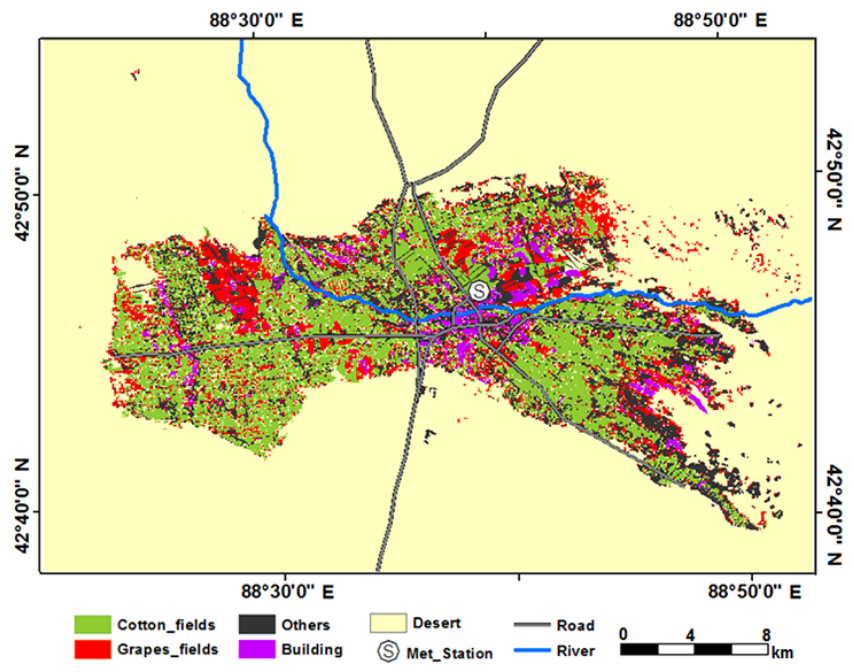

Figure 5. Land cover classification map (2010) derived from a Landsat image (13 August 2010).

soils, are shown in Fig. S10 (Supplement), clearly demonstrating regular temporal patterns due to the chosen irrigation and fertilization schedules.

The seasonal variation in the diel variation in the biogenic net NO flux from soils of land use types "grape soils" and "cotton soils" are shown in Fig. 7. Results of the biogenic net NO fluxes from desert soils are not shown. Despite very high values of soil temperature, the net NO fluxes from the Tohsun Oasis's desert soils are $\ll 0.46 \mathrm{ng} \mathrm{m}^{-2} \mathrm{~s}^{-1}$ due to the extremely low gravimetric soil water content assumed for Tohsun's desert soils $\left(\theta_{\mathrm{g}, \mathrm{desert}}=0.0028\right)$. The highest NO emissions were observed from grape soils (3220 $\mathrm{ng} \mathrm{m}^{-2} \mathrm{~s}^{-1}$ ), while the highest $\mathrm{NO}$ emissions from cotton soils only reached $0.6 \mathrm{ng} \mathrm{m}^{-2} \mathrm{~s}^{-1}$. Considering the entire growing period, biogenic net NO fluxes from grape soils dominate and even exceed those from cotton soils by a factor of $1-2 \times 10^{3}$ on average. In both soils, the seasonal and 

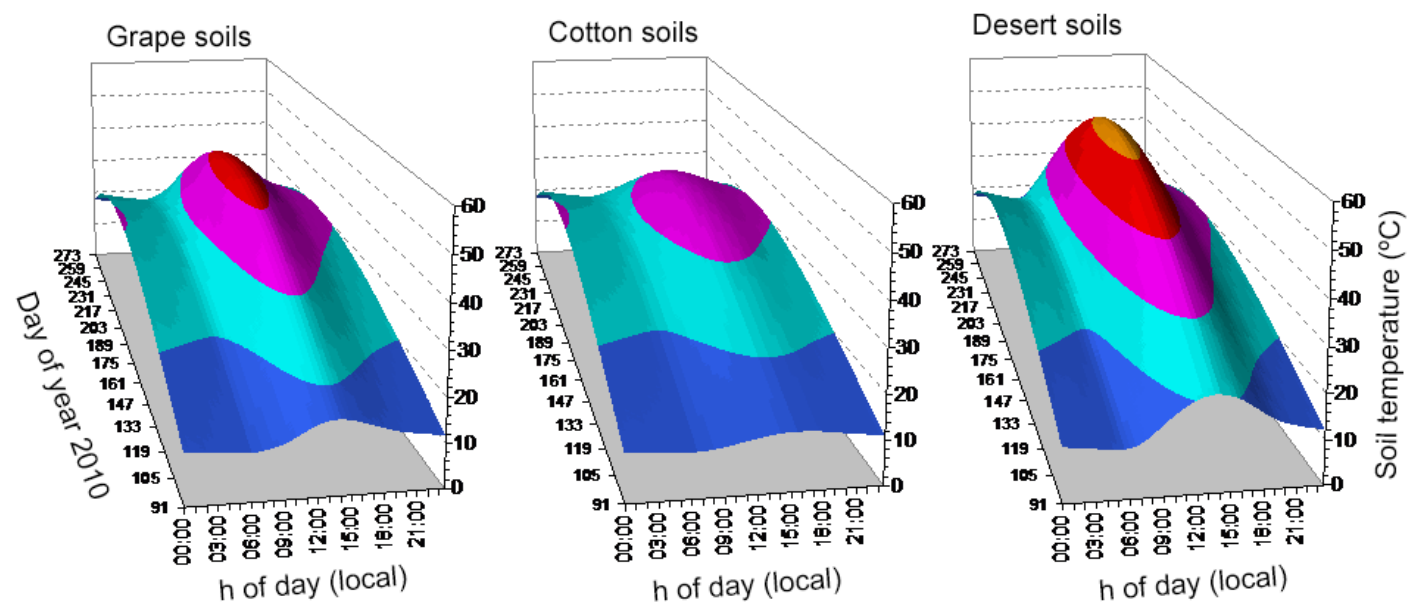

Figure 6. Seasonal variation in the diel soil temperature (30 min resolution) for grape soils, cotton soils, and desert soils of the Tohsun Oasis for the entire growing period of 2010 (1 April (DOY 90)-30 September (DOY 273)).

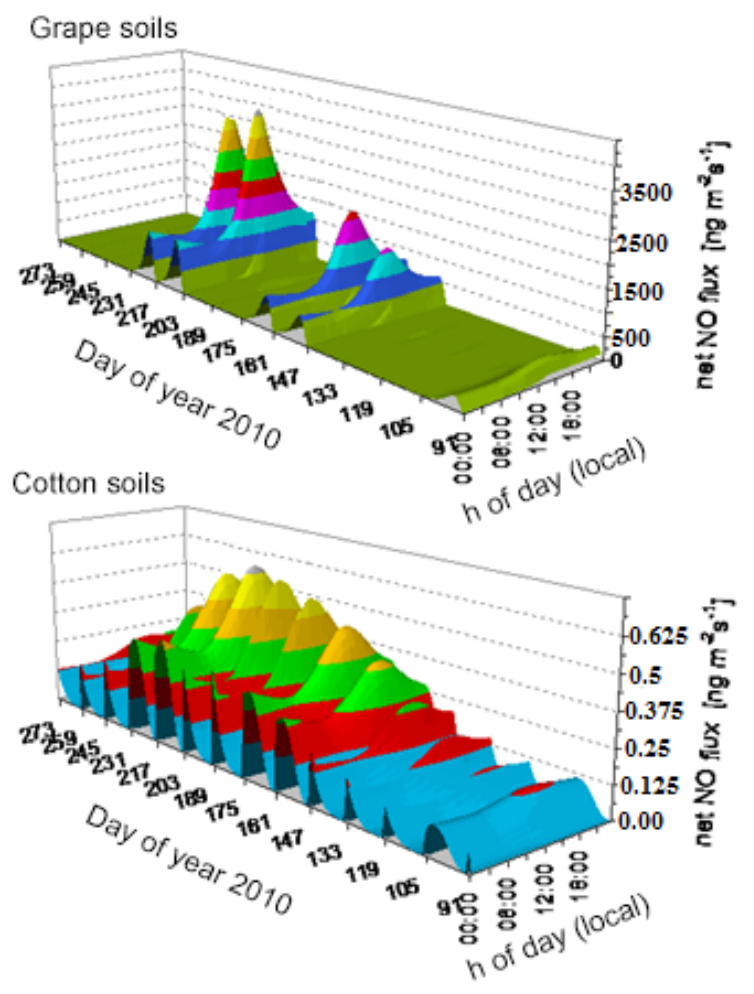

Figure 7. Seasonal variation in diel net NO flux (at $30 \mathrm{~min}$ resolution) for grape soils and cotton fields of the Tohsun Oasis for the entire growing period of 2010 (01 April (DOY 90)-30 September (DOY 273)). All data are given in terms of mass of $\mathrm{N}$.

diel variations in the net NO fluxes clearly mirror those of the corresponding soil temperature. On the seasonal scale, there is striking evidence for the impact of the chosen irrigation schedules particularly on the net NO fluxes from cotton soils (through the assumed regular 2-weekly variations in the cor- responding gravimetric soil moisture content). Immediately after (flooding) irrigation, soils might be waterlogged to prevent any diffusion of gasses out of the soil, but even after the evaporation of the surface waters, the chosen "dryingout" curves (see Supplement Fig. S9) prescribe $\theta_{\mathrm{g}}$ values of 0.514 (grape soils) and 0.586 (cotton soils), which are well above the corresponding values in field capacity conditions. There, soil diffusivity and soil microbial processes are severely suppressed (cf. Skopp et al., 1990). This is clearly reflected in the results of laboratory incubations (see Fig. 4), where the corresponding net potential NO fluxes are close to zero for $\theta_{\mathrm{g}}>0.4$. Near the end of the chosen 14-day irrigation period, $\theta_{\mathrm{g}}$ values reach 0.086 and 0.167 for grape soils and cotton soils, respectively. As a result, soil diffusivity is no longer limited in the two soils, but soil microbial processes in cotton soils are still far from their maximum activity level $\left(\theta_{\mathrm{g}, \mathrm{opt}}=0.021\right)$, while soil microbial processes in grape soils have even passed their maximum activity level $\left(\theta_{\mathrm{g}, \mathrm{opt}}=0.146\right)$. This is why biogenic net NO fluxes from grape soils of the Tohsun Oasis dominate those from cotton soils. Furthermore, the impact on net NO emission by fertilizer application on 1 April (DOY 91), 27 May (DOY 147), 10 June (DOY 161), 22 July (DOY 203), and 5 August (DOY 217; Fig. S10, Supplement) amplifies the already higher net NO fluxes from grape fields. As a consequence, NO emissions from cotton soils can be neglected if compared with emissions from grape soils, even though the net potential emission of cotton soils is more than 3 times higher than for grape soils. It should, however, be emphasized that a small change to the low optimum soil moistures of cotton soils may cause higher $\mathrm{NO}$ emissions than initially estimated. 


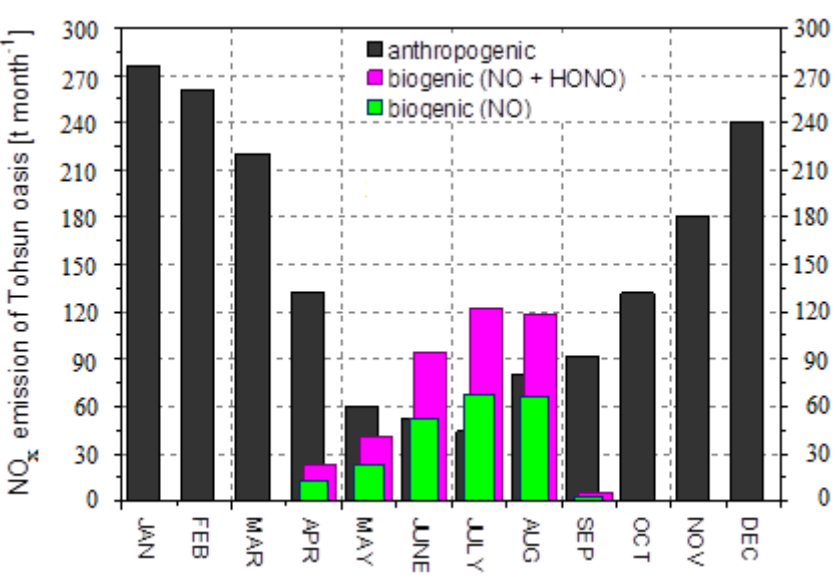

Figure 8. Anthropogenic $\mathrm{NO}_{x}$ emissions vs. soil biogenic from $\mathrm{NO}$ and HONO emissions of the Tohsun Oasis in 2010; biogenic emissions of nitrous acid (HONO) have been estimated according to Oswald et al. (2013). All data are given in terms of mass of $\mathrm{N}$.

\subsubsection{Monthly soil biogenic emissions of NO and HONO from the Tohsun Oasis (bottom-up)}

Given the areal contributions of the three land use types of the Tohsun Oasis $\left(1117,80\right.$, and $150 \mathrm{~km}^{2}$ for desert, grape, and cotton soils), the corresponding monthly bottom-up biogenic NO and HONO emissions have been calculated by (a) summing up 30 min data of related biogenic net NO fluxes (presented in the preceding section) for each month of the growing period (April-September) and (b) multiplying the results by the area of appropriate land use types. Based on the results of Oswald et al. (2013), monthly biogenic emissions of nitrous acid (HONO) have been calculated by landuse-type-specific factors applied to the monthly means of biogenic NO emissions from grape and cotton soils (see Sect. 2.3.4). For comparison with anthropogenic emissions, respective numbers of monthly soil biogenic NO and $\mathrm{HONO}$ emissions have been multiplied by the respective ratios of corresponding molecular weights $\left(M_{\mathrm{N}} / M_{\mathrm{NO}}, M_{\mathrm{N}} / M_{\mathrm{HONO}}\right)$ and are shown in terms of mass of N Fig. 8 (NO: green bars; NO+HONO: pink bars). Summing up the monthly data of $\mathrm{NO}$ emissions for the entire oasis, corresponding totals (calculation of grapes+cotton+desert) of April, May, June, July, August, and September are 13, 23, 52, 68, 66 and $3 \mathrm{t}$, respectively (see Fig. 8). Corresponding monthly bottom-up data for HONO are 10 (April), 19 (May), 42 (June), 55 (July), 53 (August) and $2.4 \mathrm{t}$ (September), respectively. It is worth noting that the bottom-up biogenic soil emissions at the monthly scale seem to be under the primary control of the soil temperature; indeed, the seasonal variation in the soil biogenic emissions mirrors greatly that of the soil temperature (see Figs. 6 and S8). Particularly during July, when soil temperatures are highest, both monthly biogenic soil NO emissions (68t) and soil HONO emissions ( $55 \mathrm{t}$ ) are also highest. It should be stressed, however, that the estimated HONO emissions are an upper bound to the HONO source since we used the ratio for the optimum condition $\left(\left(F_{\mathrm{N}_{\text {,opt }}}(\mathrm{HONO})\right.\right.$ to $\left.F_{\mathrm{N}_{\text {,opt }}}(\mathrm{NO})\right)$. The lower bounds can be determined when the HONO emissions source is omitted (see Fig. 8).

\subsubsection{Monthly anthropogenic emissions from the Tohsun Oasis (bottom-up)}

Annual anthropogenic $\mathrm{NO}_{x}$ emissions (in terms of $\mathrm{N}$ ) of the Tohsun Oasis have been determined from published information on annual consumption of different fossil fuel types and related $\mathrm{NO}_{x}$ emission factors, which are widely used in China (see Sect. 2.4). The results of the Tohsun Oasis's $\mathrm{NO}_{x}$ emissions per fuel type are shown in Fig. S11 (see Supplement). Like other parts of China, coal combustion is the largest contributor to $\mathrm{NO}_{x}$ emissions and accounts for approximately $58 \%(1512 \mathrm{t})$ of the $\mathrm{NO}_{x}$ emission inventory. As the second largest contributor, coke combustion contributed about $10 \%$. Monthly anthropogenic emissions (given in terms of mass of $\mathrm{N}$ ) have been calculated from Tohsun County's annual $\mathrm{NO}_{x}$ emission data, which were downscaled by appropriate mean monthly percentages (see Sect. 2.4); corresponding results are also shown in Fig. 8 (black bars). As expected, the overwhelming part of anthropogenic $\mathrm{NO}_{x}\left(180-276 \mathrm{t} \mathrm{N}\right.$ month $\left.{ }^{-1}\right)$ was emitted in the winter, when air temperatures (well below $0^{\circ} \mathrm{C}$; see Fig. 2) necessitate substantial domestic heating (predominantly by coal), while in July (approximately $+35^{\circ} \mathrm{C}$ ) anthropogenic $\mathrm{NO}_{x}$ emissions shrank to approximately $1 / 10$ of the winter value $\left(45 \mathrm{t} \mathrm{N} \mathrm{month}^{-1}\right)$, which might mainly be attributed to traffic emissions.

\subsubsection{Soil biogenic vs. anthropogenic emissions of the Tohsun Oasis}

On an annual basis (not shown), anthropogenic sources contributed $81.4 \%$, and biogenic sources $18.6 \%(10.3 \% \mathrm{NO}$, $8.3 \% \mathrm{HONO}$ ), to the Tohsun Oasis's total emissions (2174t, in terms of $\mathrm{N}$ ) of reactive nitrogen in 2010 . However, if only the growing period (April-September) is considered, where $40 \%$ (865 t) of the Tohsun Oasis's total annual emissions occur, the anthropogenic emissions contribute about $53.2 \%$ and biogenic sources about $46.8 \%$ (26.0\% NO, $20.8 \% \mathrm{HONO})$. As already mentioned in Sect. 3.1.3, soil biogenic emissions at monthly scales seemed to be primarily controlled by the soil temperature. Consequently, during June, July, and August, total biogenic emissions ( $\mathrm{NO}$ and $\mathrm{HONO}$ ) exceeded anthropogenic emissions by factors of $1.8,2.8$, and 1.5 , respectively (see Fig. 8). Therefore, biogenic soil emissions of NO and $\mathrm{HONO}$ during the growing period are much more important contributors to the regional $\mathrm{NO}_{x}$ budget than previously thought. 


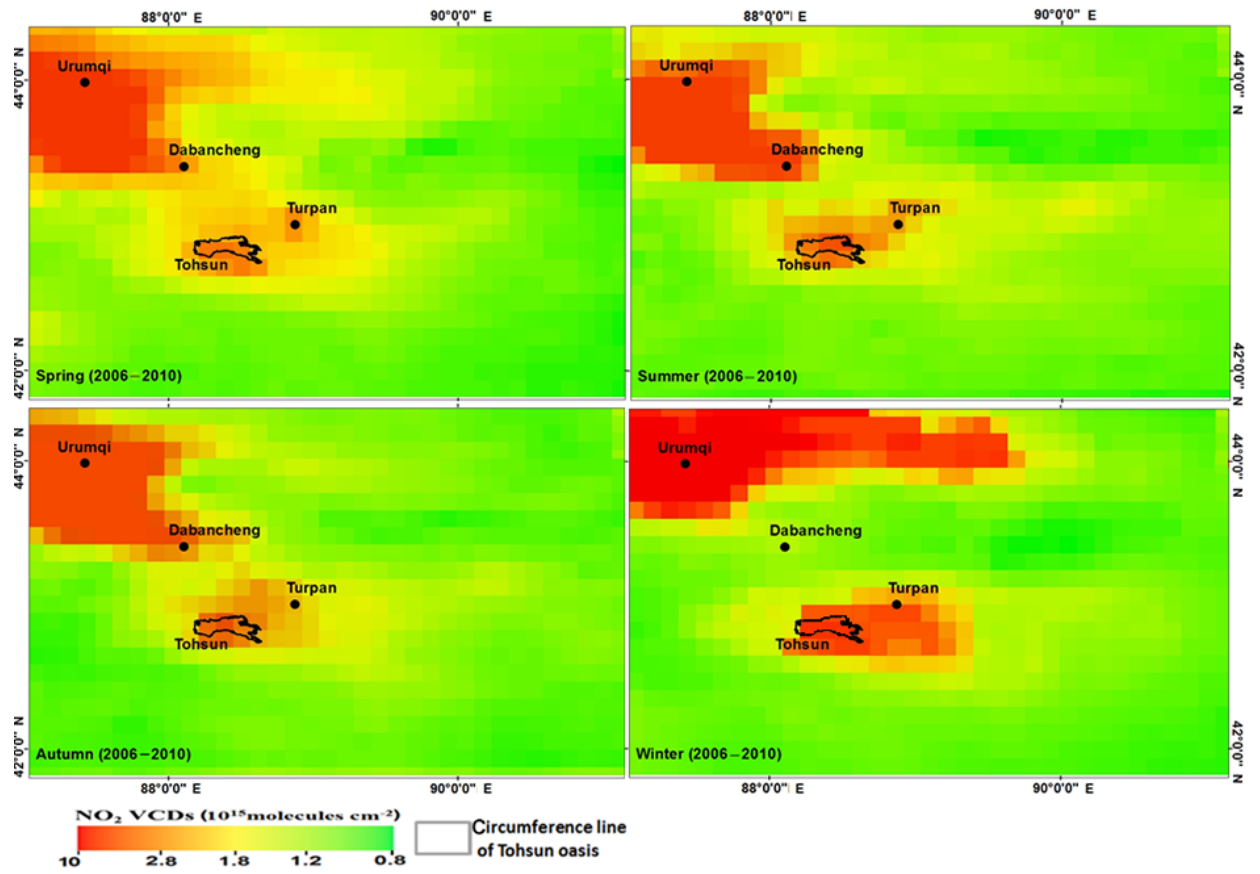

Figure 9. Seasonal 5-year-mean tropospheric vertical column densities of $\mathrm{NO}_{2}$ (2006-2010); the "circumference line" represents the agriculturally managed part of the Tohsun Oasis $\left(230 \mathrm{~km}^{2}\right)$.

\subsection{Top-down satellite-derived total $\mathrm{NO}_{x}$ emissions from the Tohsun Oasis}

\subsubsection{Spatiotemporal variation in the tropospheric $\mathrm{VCD}_{\mathrm{NO}_{2}}$ measured from satellite}

Figure 9 shows the seasonal means for spring, summer, autumn, and winter (from 2006 to 2010) of the tropospheric $\mathrm{NO}_{2} \mathrm{VCD}$ around the Tohsun Oasis. Comparing the mean distribution (2006-2010) of the different seasons, it is clearly visible that enhanced values are found over the area of the Tohsun Oasis (compared to the surrounding desert) for all seasons. Even stronger enhancements of $\mathrm{VCD}_{\mathrm{NO}_{2}}$ values are also found in other regions, which are always dominated by anthropogenic emissions, especially the growing city of Urumqi (cf. Mamtimin and Meixner, 2011). To investigate these seasonal and spatial variations in more detail, time series of monthly means are calculated for four selected areas (see Fig. 3): an area exclusively used for agriculture (A: study area), an area of mixed land use (B: agricultural and urban), a large urban area (C: Urumqi), and a desert area (D). The seasonal variation in mean tropospheric $\mathrm{VCD}_{\mathrm{NO}_{2}}$ of areas A-D is shown in Fig. 10. These data can be distinctively classified: highest $\mathrm{VCD}_{\mathrm{NO}_{2}}$ values $\left(3-15 \times 10^{15}\right.$ $\mathrm{NO}_{2}$ molecules $\mathrm{cm}^{-2}$ ) over the large urban area of Urumqi (C), $1-6.5 \times 10^{15} \mathrm{NO}_{2}$ molecules $\mathrm{cm}^{-2}$ over the Tohsun Oasis (A) and the Tohsun and Turpan area (B), and less than $1 \times 10^{15} \mathrm{NO}_{2}$ molecules $\mathrm{cm}^{-2}$ over the chosen desert area (D). From these seasonal cycles, clear indications of the relative contributions from fossil fuel combustion and soil emissions can be drawn: over Urumqi (C), clear maxima are found during winter, indicating the dominating contribution from fossil fuel combustion, while there are evidently clear minima during the summer months. In contrast, over the desert (D), where only low $\mathrm{VCD}_{\mathrm{NO}_{2}}$ values prevail, small but distinctive maxima are found during summer, which might be caused by soil emissions. Here, we need to mention that the desert $\mathrm{VCD}_{\mathrm{NO}_{2}}$ values are higher than the $\mathrm{NO}$ emission of the GGTP model results (see Supplement Sect. S1.9, Fig. S6). This is indeed an interesting finding which can be attributed to the fact that, in the desert region, a small but still substantial diurnal variation in soil moisture is present. However, in our GGTP model, we used a constant value for the soil moisture (0.0028); as a result, the diurnal cycle of soil moisture was not considered in the model calculation. It might indeed indicate that the desert soil emissions are underestimated. Alternatively, it might also be partly caused by inflow from $\mathrm{NO}_{x}$-reach air from the surrounding regions.

Over the Tohsun Oasis (A) and Tohsun and Turpan area (B), a clear maximum, although 2-3 fold lower than that over (C), is also found in every winter and is certainly related to fossil fuel combustion during the heating period. Unique for all seasonal cycles are secondary maxima found over (A) and (B) during the summer months, which amount to approximately half of the winter maxima and indicate that, during summer, soil emissions substantially contribute to total $\mathrm{NO}_{x}$ emissions. 


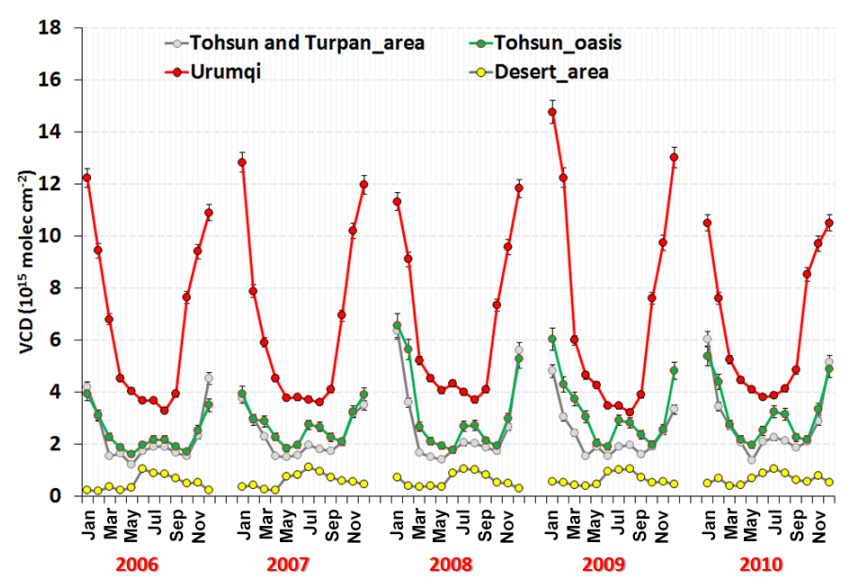

Figure 10. Monthly mean tropospheric $\mathrm{NO}_{2}$ VCD during 20062010 over selected areas (unit: $10^{15}$ molecules $\mathrm{cm}^{-2}$ )

\subsubsection{Monthly total $\mathrm{NO}_{x}$ emissions from the Tohsun Oasis (top-down)}

As described in Sect. 2.5.2, top-down monthly total $\mathrm{NO}_{x}$ emissions (particularly from anthropogenic and biogenic sources) of the Tohsun Oasis were calculated from satellitederived, background-corrected $\mathrm{VCD}_{\mathrm{NO}_{2}}$ over the Tohsun Oasis and the characteristic lifetime of $\mathrm{NO}_{x}, \tau_{\mathrm{NO}_{x}}$ (with respect to its reaction with the hydroxyl radical $\mathrm{OH}$ ). In addition, a correction for the partitioning between $\mathrm{NO}$ and $\mathrm{NO}_{2}$ in the atmosphere has to be made. For that purpose, we multiply the $\mathrm{NO}_{2}$ values by the typical ratio between $\mathrm{NO}_{x}$ and $\mathrm{NO}_{2}$ of about 1.3 (see, e.g., Seinfeld and Pandis, 2012). The results are shown in Fig. 11. Since a prescribed and constant value for $\tau_{\mathrm{NO}_{x}}(4 \mathrm{~h})$ has been applied, the seasonal course of monthly total $\mathrm{NO}_{x}$ emissions is directly proportional to that of $\mathrm{VCD}_{\mathrm{NO}_{2}}$ over the area of the Tohsun Oasis ((A) in Fig. 10). In 2010, the highest total $\mathrm{NO}_{x}$ emissions were observed in January and December (103-93 $\mathrm{ng} \mathrm{m}^{-2} \mathrm{~s}^{-2}$, in terms of $\mathrm{N}$ ), and the lowest (30-33 $\mathrm{ng} \mathrm{m}^{-2} \mathrm{~s}^{-2}$ ) in May, September, and October (see Fig. 11). Between July and August, there is the already mentioned secondary maximum of total $\mathrm{NO}_{x}$ emissions $\left(53 \mathrm{ng} \mathrm{m}^{-2} \mathrm{~s}^{-2}\right)$, approximately half of the value in January and December, and approximately twofold greater than the values of May, September, and October.

\subsection{NO $\mathrm{N}_{x}$ emissions of the Tohsun Oasis: bottom-up vs. top-down}

Finally, we compare the satellite-derived (top-down) total $\mathrm{NO}_{x}$ emissions of the Tohsun Oasis with the bottom-up total emission estimates (anthropogenic + biogenic) for the year 2010. As mentioned before (see Sect. 2.3.4), we calculated the ratio of bottom-up emissions at the satellite overpass (13:00 LT) and the daily average emissions to estimate the effect of the diurnal emissions cycle. The highest ratios

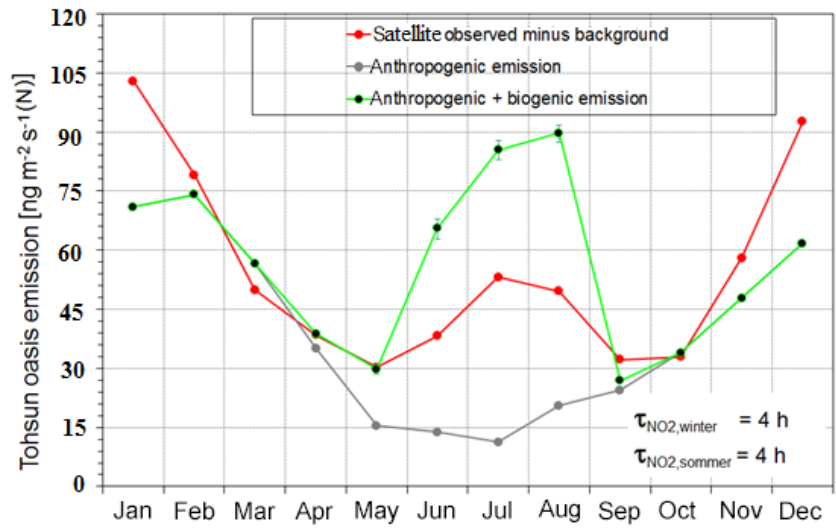

Figure 11. Monthly mean top-down emissions (from satellite observations) are compared to bottom-up (soil biogenic and anthropogenic) and anthropogenic emissions (in terms of $\mathrm{ng} \mathrm{m}^{-2} \mathrm{~s}^{-1}$, $\mathrm{N}$ ). The biogenic bottom-up emissions around 13:00 LT (at satellite overpass) are selected. They are systematically higher than the daily averages (see Fig. S12).

are found for July and August (2.4), while it is only 1.01 for April (see Fig. S12).

Monthly means of bottom-up biogenic emissions at satellite overpass (13:00 LT) with consideration to the diurnal cycle of the bottom-up estimates from the Tohsun Oasis are also shown in Fig. 11. Bottom-up anthropogenic $\mathrm{NO}_{x}$ emissions are shown individually to emphasize the contribution of soil biogenic emissions (NO+HONO).

The seasonal course of the bottom-up total emissions (anthropogenic + biogenic; in terms of N) qualitatively exhibits nearly the same shape as the seasonal course of the top-down total $\mathrm{NO}_{2}$ emissions (in terms of $\mathrm{N}$ ). Interestingly, the second maximum in summer is only found if the soil emissions are taken into account. This finding confirms that during summer soil emissions play an important (if not the dominant) role in the Tohsun Oasis's total emissions. However, wellquantified agreement between bottom-up and top-down total emissions can be observed for the months of April, May, and October. For the months of March, June, July, and August, total bottom-up emissions are always higher than the top-down ones between 10 and $62 \%$. This finding seems to confirm the soil's biogenic emission'evidence for the tropospheric $\mathrm{NO}_{x}$ through the impact of monthly variation in soil temperature, irrigation schedules, and fertilizer application. The most important error sources of the bottom-up and topdown emission estimates are discussed below.

\section{Top-down emission estimates}

a. Satellite retrieval: the air mass factor (AMF) has to be calculated for the conversion of the retrieved slant column densities into the vertical column densities. Uncertainties in the AMF can lead to uncertainties in the derived $\mathrm{NO}_{2} \mathrm{VCD}$ of about $50 \%$. Here, particular assump- 
tions on the trace gas profile and the surface albedo have to be made. For $\mathrm{NO}_{2}$, vertical profiles from a global model (TM4; see Sect. 2.5.1) with a rather coarse spatial resolution are used. The derived $\mathrm{NO}_{2}$ VCDs probably underestimate the true $\mathrm{NO}_{2}$ VCDs because the true $\mathrm{NO}_{2}$ profile peaks more closely to the ground than the profile used in the satellite retrieval. It should be noted that the uncertainties in the spectral retrieval are much smaller because many measurements are averaged. As a consequence, the true AMF is probably smaller than the one used in the OMI retrieval, and thus the $\mathrm{VCD}_{\mathrm{NO}_{2}}$ from the operational product probably underestimates the true tropospheric $\mathrm{VCD}_{\mathrm{NO}_{2}}$. In contrast, the surface albedo used in the operational product is very similar to those from other data sets (MODIS and MERIS). Here, it is interesting to note that the spatial patterns of the surface albedo and the tropospheric $\mathrm{VCD}_{\mathrm{NO}_{2}}$ show no similarities.

b. Assumption of the $\mathrm{NO}_{x}$ lifetime of $4 \mathrm{~h}$ : the lifetime of $\mathrm{NO}_{x}$ in the troposphere depends on season and altitude and varies from several hours to several days. Due to the lower winterly $\mathrm{OH}$ concentration, lifetime in winter is longer than corresponding values in summer. However, to keep the estimation of the top-down inventory simple, we used a temporally constant mean lifetime of $4 \mathrm{~h}$, which leads to a certain overestimation of the emissions in winter. Nevertheless, the considered lifetime within the study is a good approximation for the growing season, which is the focus of the study. Thereby, the potential uncertainties might be neglected if one considers the uncertainties that may be caused by the AMF.

c. Satellite overpass time period: top-down emission estimates are only valid for the time of the satellite overpass (around 13:00 LT) and a few hours before. Thus, we compared the top-down emissions to the results from the bottom-up emissions during the time of the satellite overlap (Fig. 11). Fortunately, the soil emissions during the satellite overpass time are strongest because of the high temperatures around noon.

\section{Bottom-up emission estimates}

a. Soil biogenic NO: the soil temperature at a 30 min resolution is calculated by using satellite-derived surface temperature and in situ measurements. The interpolation of the satellite-derived data was done by a thirdorder polynomial. From sensitivity analysis for secondand third-order models (see Sect. 2.3.3), we found that the uncertainties of the derived temperatures are up to about $6^{\circ} \mathrm{C}$. As a consequence, the interpolation of the data just by the third-order polynomial fit yielded the most consistent results. Substantial deviations of soil temperatures (from the interpolated values) between day 115 and day 225 might be unlikely since surface temperatures in (hyper)arid regions (even with sparse vegetation covering) are predominantly controlled by insolation only as long there is no impact of (convective) precipitation (indeed, Turpan's meteorological station did not report any precipitation events during the entire growing period). Since the dependence of the NO flux on soil temperature is exponential (see Sect. 2.3.4), by taking into consideration errors of soil temperature $\left(1.5-2.5^{\circ} \mathrm{C}\right)$ at $Q_{10}=2$, the calculated relative errors of NO account for $20 \%$, so that a total uncertainty of $25 \%$ was assumed for the NO emission estimates.

b. Soil biogenic HONO: since the NO and HONO emissions have a similar dependence on soil moisture for soil properties in arid climate conditions (Oswald et al., 2013), we used the land-use-specific constant scale factor, namely the ratio of HONO and NO releases for the optimum conditions, to estimate the HONO emissions $\left(\left(F_{\mathrm{N} \text {,opt }}(\mathrm{HONO})\right.\right.$ to $\left.F_{\mathrm{N} \text {,opt }}(\mathrm{NO})\right)$. Nevertheless, the optimum soil water content $\left(\mathrm{SWC}_{\mathrm{opt}}\right)$ has a strong influence on the ratio of $F_{\mathrm{N}_{\text {,opt }}}(\mathrm{HONO})$ to $F_{\mathrm{N} \text {,opt }}(\mathrm{NO})$. We used this ratio for the calculation of monthly HONO emissions by scaling corresponding NO emissions. However, particularly for cotton soil, the value of the optimum gravimetric soil water content for NO $(2.1 \%)$ is slightly lower than the corresponding value for $\mathrm{HONO}$ (3.6\%; see Oswald et al., 2013). Taking the relative errors of the underlying concentration measurements, and the resulting scale factor into account, a relative error of the calculated optimum HONO emissions accounts for $10 \%$. It is difficult, however, to estimate the total uncertainty of the calculated HONO emissions, because it is not clear how representative the emissions ratios determined by Oswald et al. (2013) are for the actual emissions from the Tohsun Oasis. However, we can safely assume that these HONO emissions lie between zero and the value shown in Fig. 8, which constitute emissions for optimum conditions. Thus, we estimate the total uncertainty of the HONO emissions to be about $50 \%$.

We therefore expect the uncertainty of total biogenic bottom-up emissions (NO+HONO) to be about $40 \%$. Nevertheless, these uncertainties do not question the basic message of the study.

c. Anthropogenic $\mathrm{NO}_{x}$ : furthermore, one should keep in mind that the percentage factors for temporal downscaling of annual anthropogenic $\mathrm{NO}_{x}$ emissions of the Tohsun Oasis to monthly have to be adapted from the growing city of Urumqi.

Because of these uncertainties, the good agreement between top-down and bottom-up emission estimates should be treated with caution. Nevertheless, the agreement between bottom-up and top-down estimates provides support for the 
broader applicability of the lab-derived HONO-NO emission relationships in space and time. The combination of independent methods applied in our present study was the first attempt to compare soil NO emissions of different scales, ranging from the size of a soil sample to the size of a satellite pixel. Nevertheless, some improvements in these methods for future work might be necessary:

a. including the derivation of individual $\mathrm{NO}$ and $\mathrm{HONO}$ net release rates for bottom-up biogenic emissions from a series of simultaneous incubation experiments in the laboratory under well-defined conditions (full soil temperature and gravimetric soil moisture scales),

b. temporally high resolution in situ measurements of topsoil temperature and gravimetric soil moisture by suitable (and simple) sensors at representative sites of all considered land use types (at least during the growing period),

c. the temporally resolved consideration of the $\mathrm{NO}_{x}$ lifetime for top-down emission estimates.

\section{Summary}

This study focused on the investigation and quantification of biogenic NO and HONO emissions from the agriculturally managed soils of the Tohsun Oasis (i.e., from soils of grape and cotton cultivation). Biogenic emissions of nitrous acid (HONO, concurrently emitted with NO) were also estimated using scaling factors applied to the calculated NO emissions. The following methodology was applied: firstly, the Geoscience General Tool Package (GGTP) was developed to obtain the soil temperatures and classification of land use types in the oasis from Landsat data. Secondly, mean diel and land-use-specific variations in the normalized soil temperature, gravimetric soil moisture content, and fertilizer factors were assimilated from the (sparsely) available data sources (of different spatial and temporal scales as well as data quality). These have been used to calculate the mean monthly land-use-specific bottom-up biogenic NO emissions from net potential NO fluxes, which in turn have been derived from laboratory incubation of soil samples from the three considered land use types (cotton, grape, and desert soils). Thirdly, land-use-specific factors of HONO to biogenic NO emissions from grape and cotton soils were applied to calculate the monthly biogenic bottom-up HONO emissions during the growing period. Fourthly, data for anthropogenic $\mathrm{NO}_{x}$ emissions (downscaled from annual to monthly values) were estimated and compared to the mean monthly soil biogenic emissions (NO+HONO). Fifthly, total top-down $\mathrm{NO}_{x}$ emissions from the Tohsun Oasis have been derived from satellite observations (monthly means of vertical column densities of $\mathrm{NO}_{2}, \mathrm{VCD}_{\mathrm{NO}_{2}}$ ) and prescribed values of the characteristic lifetime of $\mathrm{NO}_{x}, \tau_{\mathrm{NO}_{x}}$ (with respect to its reaction with the hydroxyl radical $\mathrm{OH})$. Finally, we compared the biogenic bottom-up emissions at midday (13:00 LT) to that of the topdown emissions with the consideration of the diurnal cycle of bottom-up estimates.

The importance of soil biogenic emissions to the regional $\mathrm{NO}_{x}$ budget of the Tohsun Oasis has been demonstrated by the comparison of monthly biogenic soil emissions (NO and HONO, expressed in terms of $\mathrm{N}$ ) and the corresponding anthropogenic $\mathrm{NO}_{x}$ emissions (in terms of $\mathrm{N}$ ). During the growing period, particularly between June and August, biogenic emissions constitute up to double that of anthropogenic emissions. From the three considered land use types of the Tohsun Oasis (desert, grape, and cotton soils), the soil biogenic emissions from grape soils (fertilized and irrigated) dominated the summertime soil biogenic emissions of the oasis, emissions from cotton soils (fertilized and irrigated) were several orders of magnitude lower (particularly because of the soil's physical nature and the chosen irrigation schedule), and soil biogenic emissions from desert soils could be completely neglected. It should be noted that the contribution from cotton soils might be considerably higher for other oases. During winter, the Tohsun Oasis's soils are frozen and biogenic emissions are virtually zero; thus, total $\mathrm{NO}_{x}$ emissions of the Tohsun Oasis during that season are exclusively due to anthropogenic emissions. As a consequence of both anthropogenic and biogenic contributions, the seasonal (monthly) variation in total emissions is characterized by two peaks (a strong peak in winter, and a weaker, secondary peak in summer). However, the uncertainty of the total biogenic bottom-up emission estimates is estimated to be about $40 \%$.

The monthly variation in the top-down total emissions (derived from satellite observations) reveals identical two-peak shapes and agrees qualitatively and truly satisfactorily with that of bottom-up emissions. Also, a good quantitative agreement between the top-down and the bottom-up estimates is found. Here it should be noted that the emissions around noon (the satellite overpass time) are up to about 2 times higher than the daily averaged emissions during the growing season. Therefore, these results provide strong evidence that the biogenic emissions from soils of managed drylands (irrigated, fertilized) in the growing period exceed local anthropogenic emissions, hence contributing substantially to the local tropospheric $\mathrm{NO}_{x}$ levels. To conclude, soil biogenic emissions of $\mathrm{NO}$ and $\mathrm{HONO}$ during the vegetation period could be much more important contributors to the regional $\mathrm{NO}_{x}$ budget (and hence to regional photochemistry) of dryland regions than previously thought.

\section{Data availability}

The underlying research data can be accessed upon contact with the corresponding author (Buhalqem Mamtimin; buhalqem.mamtimin@mpic.de). 


\section{The Supplement related to this article is available online at doi:10.5194/acp-16-10175-2016-supplement.}

Author contributions. B. Mamtimin analyzed the data and performed the bottom-up estimates; B. Mamtimin and T. Behrendt carried out the field experiments; T. Behrendt performed laboratory experiments; B. Mamtimin and T. Wagner performed the top-down estimates; B. Mamtimin and M. Badawy developed the GGTP model; B. Mamtimin, F. X. Meixner, and T. Wagner wrote the paper; and all authors contributed to the discussion of the paper.

Acknowledgements. This work was funded through the German Research Foundation (DFG) project "DEQNO - Desert Encroachment in Central Asia - Quantification of soil biogenic Nitric Oxide" (DFG-MA 4798/1-1) and the Max Planck Society (MPG). The authors would like to thank Zhaopeng Wu for his field assistance and his substantial support before, during, and after the field campaign. We acknowledge the free use of tropospheric $\mathrm{NO}_{2}$ column data from the OMI sensor from www.temis.nl. We thank the Xinjiang Meteorological Bureau, China, and the United States Geological Survey for providing meteorological data and Landsat images, respectively. The authors would like to thank S. Beirle, E. Falge, R. Shaiganfar, Y. Wang, and J. Lampel for useful discussions.

The article processing charges for this open-access publication were covered by the Max Planck Society.

Edited by: S. E. Pusede

Reviewed by: two anonymous referees

\section{References}

Ashuri, F. A.: Der Austausch von Stickstoffmonoxid zwischen Boden und Atmosphäre unter besonderer Berücksichtigung des Bodenwassergehaltes, Einfluss kulturlandschaftlicher Verhältnisse auf den Umsatz eines Spurengases, PhD thesis, Johannes Gutenberg University Mainz, Mainz, Germany, 1-169, 2009.

Bargsten, A., Falge, E., Pritsch, K., Huwe, B., and Meixner, F. X.: Laboratory measurements of nitric oxide release from forest soil with a thick organic layer under different understory types, Biogeosciences, 7, 1425-1441, doi:10.5194/bg-7-1425-2010, 2010.

Behrendt, T., Veres, P. R., Ashuri, F., Song, G., Flanz, M., Mamtimin, B., Bruse, M., Williams, J., and Meixner, F. X.: Characterisation of NO production and consumption: new insights by an improved laboratory dynamic chamber technique, Biogeosciences, 11, 5463-5492, doi:10.5194/bg-11-5463-2014, 2014.

Beirle, S., Boersma, K. F., Platt, U., Lawrence, M. G., and Wagner, T.: Megacity emissions and lifetimes of nitrogen oxides probed from space, Science, 333, p. 1737, 2011.

Boersma, K. F., Eskes, H. J., Veefkind, J. P., Brinksma, E. J., van der A, R. J., Sneep, M., van den Oord, G. H. J., Levelt, P. F., Stammes, P., Gleason, J. F., and Bucsela, E. J.: Near-real time retrieval of tropospheric $\mathrm{NO}_{2}$ from OMI, Atmos. Chem. Phys., 7, 2103-2118, doi:10.5194/acp-7-2103-2007, 2007.
Boersma, K. F., Eskes, H. J., Dirksen, R. J., van der A, R. J., Veefkind, J. P., Stammes, P., Huijnen, V., Kleipool, Q. L., Sneep, M., Claas, J., Leitão, J., Richter, A., Zhou, Y., and Brunner, D.: An improved tropospheric $\mathrm{NO}_{2}$ column retrieval algorithm for the Ozone Monitoring Instrument, Atmos. Meas. Tech., 4, 19051928, doi:10.5194/amt-4-1905-2011, 2011.

Chameides, W. L., Fehsenfeld, F., Rodgers, M. O., Cardelino, C.,Martinez, J., Parrish, D., Lonneman, W., Lawson, D. R., Rasmussen,R. A., Zimmerman, P., Greenberg, J., Middleton, P., and Wang, T.: Ozone precursor relationships in the ambient atmosphere, J. Geophys. Res., 92, 6037-6055, 1992.

Chander, G. and Markham, B.: Revised Landsat-5 TM radiometric Calibration procedures and postcalibration dynamic ranges, IEEE Trans. Geosci. Remote Sens., 41, 2674-2677, 2003.

Chen, X. P., Cui, Z. L., Vitousek, P. M., Cassman, K. G., Matson, P. A., Bai, J. S., Meng, Q. F., Hou, P., Yue, S. C., Römheld, V., and Zhang, S. F.: Integrated soil-crop system management for food security, Proc. Natl. Acad. Sci., 108-16, 6399-6404, 2011.

Conrad, R.: Soil Microorganisms as controllers of atmospheric trace gases $\left(\mathrm{H}_{2}, \mathrm{CO}, \mathrm{CH}_{4}, \mathrm{~N}_{2} \mathrm{O}\right.$, and $\left.\mathrm{NO}\right)$, Microbiol. Rev., 60, 609640, 1996.

Crutzen, P. J.: Role of the tropics in atmospheric chemistry, in: The Geophysiology of Amazonia, edited by: Dickinson, R. E., John Wiley \& Sons, New York, 107-132, 1987.

Davidson, E. A. and Kingerlee, W.: A global inventory of nitric oxide emissions from soils, Nutr. Cycl. Agroecosys., 48, 37-50, 1997.

Delon, C., Mougin, E., Serça, D., Grippa, M., Hiernaux, P., Diawara, M., Galy-Lacaux, C., and Kergoat, L.: Modelling the effect of soil moisture and organic matter degradation on biogenic NO emissions from soils in Sahel rangeland (Mali), Biogeosciences, 12, 3253-3272, doi:10.5194/bg-12-3253-2015, 2015.

Denman, K. L., Brasseur, G. P., Chidthaisong, A., Ciais, P., Cox, P. M., Dickinson, R. E., Hauglustaine, D., Heinze, C., Holland, E. A., Jacob, D. J., Lohmann, U., Ramachandran, S., da Silva Dias, P. L., Wofsy, S. C., and Zhang, X.: Couplings between changes in the climate system and biogeochemistry, in: Climate Change 2007: The physical science basis. contribution of working group 1 to the fourth assessment report of the Intergovernmental Panel on Climate Change, edited by: Solomon, S., Qin, D., Manning, M., Chen, Z., Marquis, M., Averyt, K. B., Tignor, M., and Miller, H. L., 499-588, Cambridge, Cambridge University Press, 2007.

Diallo, D. and Mariko, A.: Field capacity (FC) and permanent wilty point (PWP) of clay soils developed on Quaternary alluvium in Niger River loop (Mali), Int. J. Eng. Res. Appl., 3, 1085-1089, 2013.

Fechner, A.: The release of nitric oxide from agriculturally managed soils of selected oases on the fringe of the Taklimakan desert (Xinjiang, P.R. China) - Investigation of fertilizers' impact (in German), MSc thesis, Institute of Geography, Johannes Gutenberg University, Mainz, Germany, 135 pp., 2014.

Feig, G. T., Mamtimin, B., and Meixner, F. X.: Soil biogenic emissions of nitric oxide from a semi-arid savanna in South Africa, Biogeosciences, 5, 1723-1738, doi:10.5194/bg-5-17232008, 2008.

Gelfand, I., Feig, G., Meixner, F. X., and Yakir, D.: Afforestation of semi-arid shrubland reduces biogenic NO emission from soil, Soil Biol. Biochem., 41, 1561-1570, 2009. 
Gödde, M. and Conrad, R.: Influence of soil properties on the turnover of nitric oxide and nitrous oxide by nitrification and denitrification at constant temperature and moisture, Biol. Fert. Soils, 32, 120-128, 2000.

Goward, S. N. and Williams, D. L.: Landsat and Earth Systems Science: Development of terrestrial monitoring, Photogr. Eng. Remote Sens., 63, 887-900, 1997.

Hao, J. M., Tian, H. Z., and Lu, Y. Q.: Emission Inventories of $\mathrm{NO}_{x}$ from Commercial Energy Consumption in China, 1995-1998, Environ. Sci. Technol., 36, 552-560, 2002.

IPCC: Climate Change 2001: The Scientific Basis, Contribution of Working Group I to the Third Assessment Report of the Intergovernmental Panel on Climate Change (IPCC), in: Chapter 4: Atmospheric Chemistry and Greenhouse Gases, edited by: Houghton, J. T., Ding, Y., Griggs, D. J., Noguer, M., van der Linden, P. J., and Xiaosa, D., Cambridge University Press, Cambridge, New York, 239-287, 2001.

Irish, R.: Landsat 7 Science Data Users Handbook, NASA Goddard Space Flight Cent., Greenbelt, Md., available at: http://landsat.gsfc.nasa.gov/wp-content/uploads/2016/08/ Landsat7_Handbook.pdf (last access: 1 August 2016), 2003.

Jensen, J. R.: Introductory Digital Image Processing: A Remote Sensing Perspective, 3rd Edn., Prentice-Hall, Upper Saddle River, 198-210, 337-401, 2005.

Jin, J. X. and Ma, X. D.: Xinjiang Statistical Yearbook 2009, China Statistics Press, Beijing, 2009.

Jin, J. X. and Ma, X. D.: Xinjiang Statistical Yearbook 2011, China Statistics Press, Beijing, 2011.

Kasibhatla, P. S., Levy, H., and Moxim, W. J.: Global $\mathrm{NO}_{x}, \mathrm{HNO}_{3}$, Pan, and NOy Distributions from Fossil-Fuel Combustion Emissions - a Model Study, J. Geophys. Res.-Atmos., 98, 7165-7180, 1993.

Kirkman, G. A., Yang, W. X., and Meixner, F. X.: Biogenic nitric oxide emissions upscaling: an approach for Zimbabwe, Global Biogeochem. Cy., 15, 1005-1020, 2001.

Kleipool, Q. L., Dobber, M. R., Haan, J. F., and Levelt, P. F.: Earth surface reflectance climatology from 3 years of OMI data, J. Geophys. Res., 113, 1-22, 2008.

Kottek, M., Grieser, J., Beck, C., Rudolf, B., and Rubel, F.: World Map of the Köppen-Geiger climate classification Updated, Meteorol. Z., 15, 259-263, 2006.

Lai, R.: Potential of desertification control to sequester carbon and mitigate the greenhouse effect, Climatic Change, 51, 35-72, 2001.

Li, Z. X., Zhu, Z. J., Yang, L. L., Yang, Z. Q., Cui, K. B., Liu, K., Liu, J., Shen, X. H., and Maihemujiang: Study on technical Countermeasure of promoting Xinjiang Raisin into International Market, Xinjiang Agricultural Science, 49, 129-135, 2012.

Liang, S., Fang, H., Morisette, J. T., Chen, M., Shuey, C. J., Walthall, C. L., and Daughtry, C. S. T.: Atmospheric Correction of Landsat ETM+ Land Surface Imagery: II. Validation and Applications, IEEE Trans. Geosci. Remote Sens., 12, 2736-2746, doi:10.1109/TGRS.2002.807579, 2002.

Lu, D., Mausel, P., Brondizio, E., and Moran, E.: Assessment of atmospheric correction methods for Landsat TM data applicable to Amazon basin LBA research, Int. J. Remote Sens., 23, 26512671, 2002.

Ludwig, J., Meixner F. X., Vogel, B., and Förstner, J.: Soil-air exchange of nitric oxide: An overview of processes, environmen- tal factors, and modeling studies, Biogeochemistry, 52, 225-257, 2001.

Ma, X. C.: Map of Xinjiang, Star Map Press, Beijing, 2010.

Mamtimin, B.: Climate of arid and semi-arid regions and the possibilities of sustainable agriculture utilization in Xinjiang (China) as an example, PhD thesis, Johannes Gutenberg University Mainz, Mainz, Germany, 1-206, 2005.

Mamtimin, B. and Meixner, F. X.: Air pollution and meteorological processes in the growing dryland city of Urumqi (Xinjiang, China), Sci. Total Environ., 409, 1277-1290, 2011.

Mamtimin, B., Behrendt, T., Badawy, M. M., Wagner, T., Qi, Y., Wu, Z., and Meixner, F. X.: Tropospheric vertical column densities of $\mathrm{NO}_{2}$ over managed dryland ecosystems (Xinjiang, China): MAX-DOAS measurements vs. 3-D dispersion model simulations based on laboratory-derived NO emission from soil samples, Atmos. Chem. Phys., 15, 867-82, doi:10.5194/acp-15-8672015, 2015.

Markham, B. L. and Barker, J. L.: Landsat MSS and TM postcalibration dynamic ranges, exoatmospheric reflectance and atsatellite temperatures, EOSAT Landsat Tech. Notes 1, Earth Obs. Satell. Co., Lanham, Md., 3-8, 1986.

Mayer, J. C., Bargsten, A., Rummel, U., Meixner, F. X., and Foken,T.: Distributed Modified Bowen Ratio method for surface layer fluxes of reactive and non-reactive trace gases, Agr. Forest Meteorol., 151, 655-668, 2011.

Meixner, F. X. and Yang, W. X.: Biogenic emissions of nitric oxide and nitrous oxide from arid and semi-arid land, in: Dryland Ecohydrology, D’Odorico, P. and Porporat, A., Springer, Dordrecht, 233-255, 2006.

Naegele, W. and Conrad, R.: Influence of soil pH on the nitratereducing microbial population and their potential to reduce nitrate tor nitric oxide and nitrous oxide, FEMS Microbiology Ecology, 74, 49-58, 1990.

Oswald, R., Behrendt, T., Ermel, M., Wu, D., Su, H., Cheng, Y., Breuninger, C., Moravek, A., Mougin, E., Delon, C., Loubet, B., Pommerening-Röser, A., Sörgel, M., Pöschl, U., Hoffmann, T., Andreae, M. O., Meixner, F. X., and Trebs, I.: HONO emissions from soil bacteria as a major source of atmospheric reactive nitrogen, Science, 341, 1233-1235, 2013.

Otter, L. B., Yang, W. X., Scholes, M. C., and Meixner, F. X.: Nitric Oxide emissions from a southern African Savanna, J. Geophys. Res., 104, 18471-18485, 1999.

Pu, Y. P.: Tulufan (Turpan) Statistical Yearbook 2008, China Statistics Press, Beijing, 2009.

Pu, Y. P.: Tulufan (Turpan) Statistical Yearbook 2010, China Statistics Press, Beijing, 2011.

Schott, J. R. and Volchok, W. J.: Thematic Mapper thermal infrared calibration, Photogramm. Eng. Remote Sens., 51, 1351-1357, 1985.

Seinfeld, J. H. and Pandis, S. N.: Atmospheric Chemistry and Physics: From Air Pollution to Climate Change, John Wiley \& Sons., chapt. 6.5, 2012.

Shi, Y., Xia, Y. F., Lu, B. H., Liu, N., Zhang, L., Li, S. J., and Li, W.: Emission inventory and trends of $\mathrm{NO}_{x}$ for China, 2000-2020, J. Zhejiang Univ.-Sci. A Appl. Phy. Eng., 15, 454-464, 2014.

Skopp, J., Jawson, M. D., and Doran, J. W.: Steady-State Aerobic Microbial Activity as a Function of Soil-Water Content, Soil Sci. Soc. Am. J., 54, 1619-1625, 1990. 
Sörgel, M., Trebs, I., Serafimovich, A., Moravek, A., Held, A., and Zetzsch, C.: Simultaneous HONO measurements in and above a forest canopy: influence of turbulent exchange on mixing ratio differences, Atmos. Chem. Phys., 11, 841-855, doi:10.5194/acp11-841-2011, 2011.

Stotzky, G., Goos, R. D., and Timonin, M. I.: Microbial changes occurring in soil as a result of storage, Plant Soil, 16, 1-18, 1962.

Su, H., Cheng, Y., Oswald, R., Behrendt, T., Trebs, I., Meixner, F. X., Andreae, M. O., Cheng, P., Zhang, Y., and Pöschl, U.: Soil Nitrite as a Source of Atmospheric HONO and OH Radicals, Science, 333, 1616-1618, doi:10.1126/science.1207687, 2011.

Van Dijk, S. M., Gut, A., Kirkman, G. A., Meixner, F. X., and Andreae, M. O.: Biogenic NO emissions from forest and pasture soils: Relating laboratory studies to field measurements, J. Geophys. Res., 107, LBA25-1-LBA25-11, 2002.

Wan, Y.: Strategy of foreign trade office of several companies to develop raisins international market, Baidu Wenku/Baidu Library published by the Government of the PR China, available at: www.wenku.baidu.com, last access: 14 November 2012.

Weggel, O.: Xinjiang (Sinkiang), Hamburg, Germany, 76 pp., 1985.
Yang, W. X. and Meixner, F. X.: Laboratory studies on the release of nitric oxide from subtropical grassland soils: the effect of soil temperature and moisture, in: Gaseous Nitrogen Emissions from Grasslands, Wallingford, England, 67-70, 1997.

Yu, J., Meixner, F. X., Sun, W., Liang, Z., Chen, Y., Mamtimin, B., Wang, G., and Sun, Z.: The biogenic nitric oxide emission from saline sodic soils in semiarid region, Northeastern China: A laboratory study, J. Geophys. Res., 113, 1-11, 2008.

Yu, J., Meixner, F. X., Sun, W., Mamtimin, B., Wang, G., Qi, X., Xia, C., and Xie, W.: Nitric oxide emissions from black soil, northeastern China: A laboratory study revealing significantly lower rates than hitherto reported, Soil Biol. Biochem., 42, 1784 1792, 2010.

Zhang, Q., Streets, D. G., Carmichael, G. R., He, K. B., Huo, H., Kannari, A., Klimont, Z., Park, I. S., Reddy, S., Fu, J. S., Chen, D., Duan, L., Lei, Y., Wang, L. T., and Yao, Z. L.: Asian emissions in 2006 for the NASA INTEX-B mission, Atmos. Chem. Phys., 9, 5131-5153, doi:10.5194/acp-9-5131-2009, 2009.

Zhou, X. Q.: China Electric Power Yearbook, China Power Press, Beijing, 2006. 